\title{
Zeolitic Imidazolate Framework Membranes for Light Olefin/Paraffin Separation
}

\author{
Xiaoli Ma ${ }^{1, *}$ and Defei Liu ${ }^{2, *(1)}$ \\ 1 Department of Materials Science and Engineering, University of Wisconsin-Milwaukee, \\ Milwaukee, WI 53211, USA \\ 2 School of Environment and Chemical Engineering, Foshan University, Foshan 528000, China \\ * Correspondence: ma26@uwm.edu (X.M.); defeiliu@icloud.com (D.L.); Tel.: +1-414-229-4767 (X.M.)
}

Received: 9 November 2018; Accepted: 21 December 2018; Published: 25 December 2018

\begin{abstract}
Propylene/propane and ethylene/ethane separations are performed by energy-intensive distillation processes, and membrane separation may provide substantial energy and capital cost savings. Zeolitic imidazolate frameworks (ZIFs) have emerged as promising membrane materials for olefin/paraffin separation due to their tunable pore size and chemistry property, and excellent chemical and thermal stability. In this review, we summarize the recent advances on ZIF membranes for propylene/propane and ethylene/ethane separations. Membrane fabrication methods such as in situ crystallization, seeded growth, counter-diffusion synthesis, interfacial microfluidic processing, vapor-phase and current-driven synthesis are presented. The gas permeation and separation characteristics and membrane stability are also discussed.
\end{abstract}

Keywords: metal-organic frameworks; zeolitic imidazolate frameworks; membranes; propylene/propane separation; ethylene/ethane separation

\section{Introduction}

With the global annual production above 200 million tonnes [1], light olefins such as ethylene and propylene are the two highest volume feedstocks of chemical industry [2-5]. They are mainly produced by steam cracking of paraffins including ethane, propane, and other light hydrocarbons. The separation of ethylene and propylene from their close-boiling paraffins is currently performed on a large scale by energy-intensive cryogenic distillation processes [2-4]. It was estimated that propylene/propane (C3) and ethylene/ethane (C2) separations based on distillation account for $0.3 \%$ of global energy use [1]. Many alternative less energy-intensive separation technologies such as extraction, adsorption, and membrane separation have been considered to supplement or replace distillations [6-9]. Among them, membrane separation appears quite attractive owing to the advantages of continuous operation, small footprint, and low energy consumption [10,11].

A variety of membranes including polymeric, facilitated transport and microporous inorganic membranes have been explored for C 3 and C2 separations. Polymer membranes remain the most studied candidate because of their low cost and ease of processing into membrane modules of high packing density such as hollow fibers [10-12]. The olefin/paraffin separations of polymer membranes have been discussed in detail in several review articles [3,4,11,12]. Because of the permeability-selectivity tradeoff and the detrimental plasticization effect, the performance of polymer membranes at industrially relevant conditions such as high feed pressure is inadequate for practical applications. Facilitated transport membranes possess superior selectivity for olefins over paraffins due to the reversible chemical bonds formed between olefins and transition metal ions, but they suffer from instability issues associated with the poisoning of carrier agents [13]. Recently, microporous inorganic membranes composed of molecular sieves such as carbon molecular sieves (CMS) [14,15], silica [16], 
zeolites [17-19], and metal-organic frameworks (MOFs) [20-23] have emerged as promising membrane candidates that combine high-resolution separation capability and excellent chemical/thermal stability. Among these materials, MOFs are a recent class of nanoporous materials constructed by metal ions/clusters coordinatively bridged by organic linkers [24-27]. Compared to traditional porous solids such as zeolites and carbons, the intriguing reticular chemistry of MOFs has led to the discovery of a wide variety of nanoporous structures that possess tunable pore size and surface chemistry properties, which can translate to interesting separation properties [28-31]. Therefore, MOFs have found applications in a broad range of membrane-based separation, purification, and reaction processes including gas separation [32-35], desalination [36,37], high-efficiency oil-water separation [38,39], organic solvent nanofiltration [40,41], pervaporation separation [42,43], pH-responsive switchable separation of similarly sized proteins [44], and catalytic membrane reactors [45,46]. In particular, zeolitic imidazolate frameworks (ZIFs), a subclass of MOFs, have shown great promise as membrane materials for olefin/paraffin separation $[47,48]$.

ZIFs are composed of transition-metal ions bridged by imidazolate linkers in a manner similar to the $\mathrm{Si}-\mathrm{O}$ bond in zeolites $[28,47,49,50]$. The zeolite-like topology has endowed ZIFs with superior thermal and chemical stabilities to the MOFs reported earlier such as MOF-5. In addition, the aperture sizes of most ZIFs are precisely defined in the range of 3 to $5 \AA$, making them highly kinetically selective for gas molecules with sub-ångström size difference [49,51,52]. To use ZIFs for membrane applications, one approach is to incorporate nanoscale ZIF crystals in polymer membranes to form mixed matrix membranes (MMMs) (Figure 1a) and the other is to fabricate continuous thin film ZIF membranes on top of macro or mesoporous supports (Figure 1b). While the MMMs have scale up advantage, it is the supported ZIF membranes that can harness the full potential of the molecular recognition capability of ZIFs to achieve highly selective separation. These molecular sieving ZIF membranes have been extensively studies over the past few years, with focuses on making thin and defect-free membranes on various types of supports and understanding their structures and gas separation properties. Many of the progresses have been discussed in several review articles [18,48,53-55]. Here, we focus on the fabrication and application of supported ZIF membranes for olefin/paraffin separation. We will discuss the representative membrane fabrication methods, membrane structure, propylene/propane and ethylene/ethane separation characteristics, as well as membrane stability.

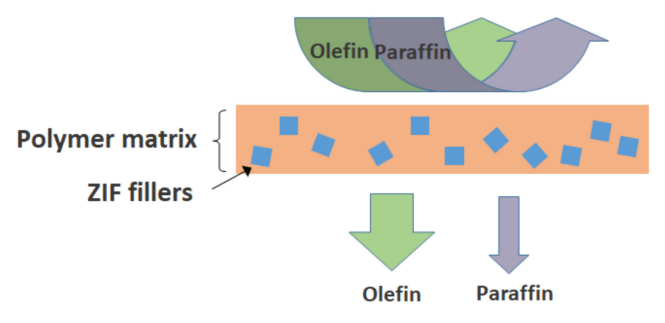

(a) ZIF-based mixed matrix membrane

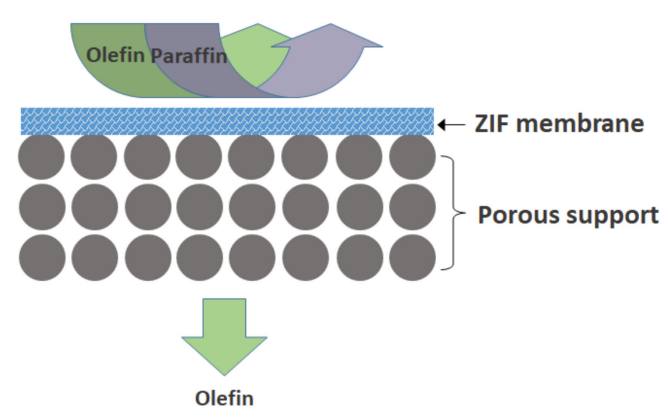

(b) Supported ZIF membrane

Figure 1. Schematic of (a) ZIF-based mixed matrix membrane and (b) supported thin film ZIF membrane.

\section{ZIF Membranes for Propylene/Propane Separation}

ZIFs were first discovered by Yaghi's group in 2006 [47]. ZIF-8 is one eminent example of ZIFs that consists of zinc ions connected by 2-methylimidazole linkers (Figure 2a,b). The aperture size of the six-membered-ring in ZIF-8 framework is determined to be 3.4 A by single-crystal X-ray diffraction. However, due to the flipping motion of the ligand upon pressure or the introduction of guest molecules, ZIF-8 does not exhibit sharp molecular sieving cut-off at $3.4 \AA$ [56,57]. Li and co-workers first studied the adsorption isotherm and kinetic uptake of propylene and propane in ZIF-8 crystals [51]. They found that, despite having a molecular size larger than $3.4 \AA$ (van der Waals diameters: propylene $=4.03 \AA$, 
propane $=4.16 \AA$ ), both propylene and propane molecules can enter the pores of ZIF-8, eventually reaching similar adsorption equilibrium. However, the diffusion rate coefficient of propylene is more than 100 times higher that of propane $\left(\left(\mathrm{D}_{\text {(propylene) }} / \mathrm{D}_{\text {(propane) }}=125\right)\right)$ (Figure $\left.2 \mathrm{c}\right)$, suggesting the great potential for the kinetic separation of $\mathrm{C} 3$ molecules. This unexpected molecular sieving property was further confirmed by other computational and experimental studies $[52,58,59]$. Through kinetic uptake rate measurements, the propylene and propane diffusivities of ZIF- 8 calculated by Koros' group are $2.9 \times 10^{-8} \mathrm{~cm}^{2} / \mathrm{s}$ and $2.0 \times 10^{-10} \mathrm{~cm}^{2} / \mathrm{s}$, respectively [52]. Thus, the effective aperture size of ZIF-8 was revealed to be in the range of 4.0 to $4.2 \AA$, between the molecular diameters of propylene and propane (Figure 2d). Based on their calculations, the propylene/propane ideal selectivity of ZIF-8 membrane was predicted to be $\sim 130$.

(a)

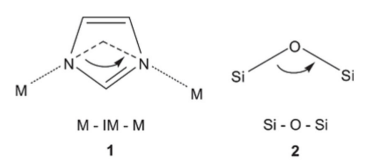

(c)

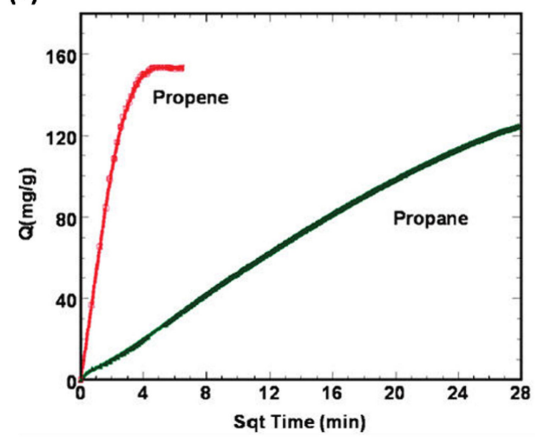

(b)

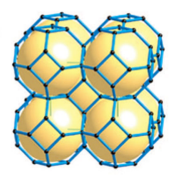

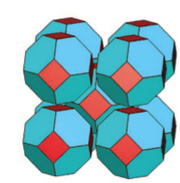

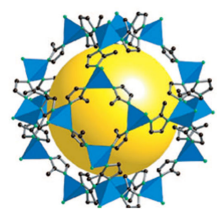

(d)

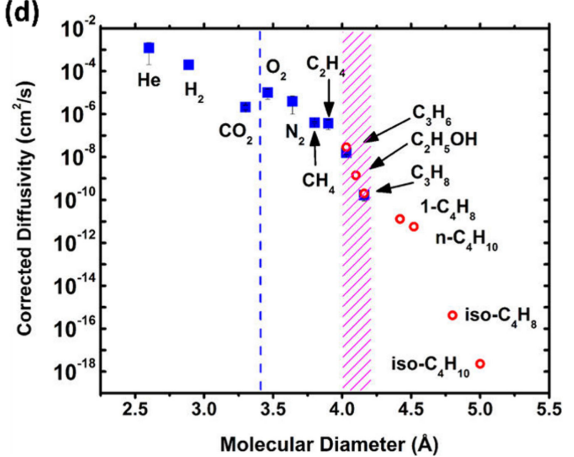

Figure 2. (a) The bridging angles in ZIFs (1) and zeolites (2) [47]. (b) SOD topology and structure of ZIF-8 [47]. (c) Propylene and propane kinetic uptake by ZIF-8 [51]. (d) Corrected diffusivities in ZIF-8 at $35{ }^{\circ} \mathrm{C}$ versus molecular diameter of probe molecules [52].

The first ZIF-8 membrane was prepared by Caro's group in 2009 and the membrane showed excellent hydrogen separation properties [60]. Lai and co-worker were the first to report the propylene/propane separation property of ZIF-8 membranes, which exhibited an average separation factor above 30 [61]. The separation performances, in terms of propylene permeability and propylene/propane selectivity, have surpassed the performance upper bound of polymer and carbon molecular sieve membranes [61]. Since then, ZIF membranes, particularly ZIF-8 membranes have attracted extensive attention for $\mathrm{C} 3$ separation.

\subsection{ZIF-8 Membranes for C3 Separation: Membrane Synthesis}

Continuous research efforts have led to the successful development of various reliable techniques for the fabrication of ZIF membranes. Here in this review, we focus on those representative ones (Figure 3). The methods developed for zeolite membranes such as in situ crystallization and seeded growth have proven effective for ZIF membranes as well. Meanwhile, the unique coordination chemistry has enabled the design of new approaches specifically suitable for ZIF membranes. Unlike the hydrothermal synthesis of many zeolites, the formation of ZIFs does not require the use of templates or the subsequent high temperature template removal process. Therefore, ZIF membranes can be prepared and activated at mild conditions such as at low temperatures in liquid medium of low toxicity or even in gas phase. Moreover, the inorganic-organic hybrid nature endows ZIFs with much improved compatibility with polymers, favoring the formation of high quality ZIF membranes on low-cost and scalable polymer supports. In order to achieve high permeance, the common challenge 
in all membrane synthesis approaches is to reduce the membrane thickness without forming defects that may compromise selectivity.

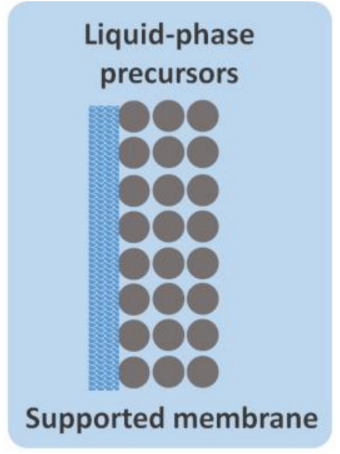

In situ synthesis

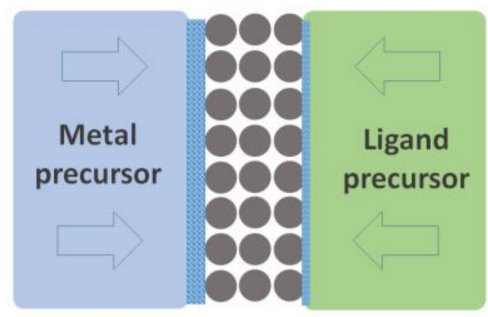

\section{Counter diffusion synthesis}

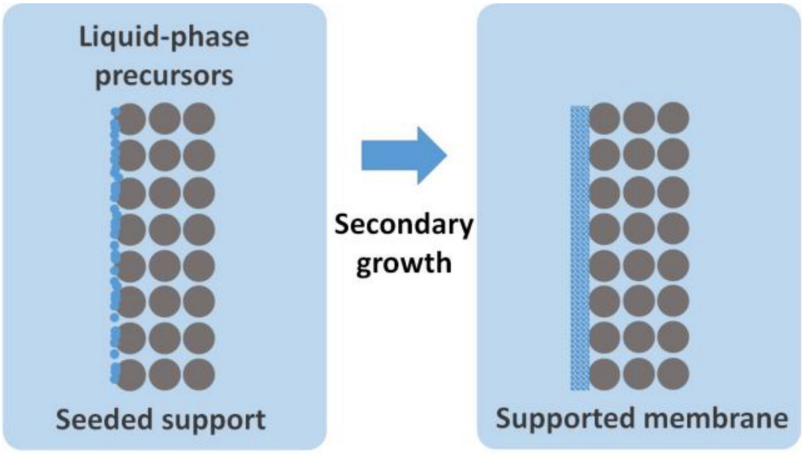

Seeded growth

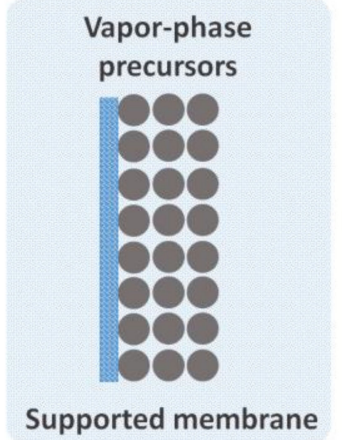

Vapor-phase synthesis

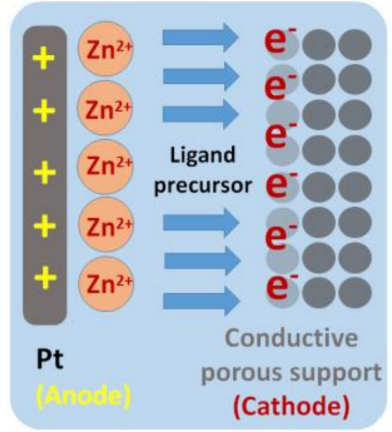

Current driven synthesis

Figure 3. Schematic of the methods developed for the synthesis of supported ZIF membranes.

\subsubsection{In Situ Crystallization}

In situ crystallization is a method widely used for zeolite membranes, in which the support is directly brought in contact with the precursor solutions for the heterogeneous nucleation and growth of a continuous membrane layer on the support surface. This method was adapted by Caro's group to synthesize ZIF-8 membranes on ceramic supports [60]. Using methanol as the solvent, a crack-free polycrystalline ZIF-8 membrane was prepared on a porous titania support by microwave-assisted in situ solvothermal synthesis. Because of its smaller diameter than the commonly used dimethylformamide (DMF) solvent and the weak interaction with the ZIF-8 framework, methanol can be easily removed from the frameworks without creating large stress to the membrane layer that may cause cracks. Sodium formate was added in the synthesis solution to promote the deprotonation of 2-methylimidazole ligand facilitating the crystal growth [60,62]. The ZIF-8 membrane synthesized has a thickness of $\sim 30 \mu \mathrm{m}$ and show molecular sieving properties for hydrogen separation with a $\mathrm{H}_{2} / \mathrm{CH}_{4}$ mixture separation factor of 11.2. In situ synthesis can also produce ZIF membranes on tubular or even hollow fiber supports. For example, $\mathrm{Xu}$ and co-workers prepared ZIF-8 membranes on the outer surface of ceramic hollow fiber supports using in situ method [63]. The nucleation and growth rates were carefully controlled by varying the composition of the precursor solution and the synthesis temperature. The hollow fiber supported membrane exhibited a $\mathrm{H}_{2} / \mathrm{CO}_{2}$ separation factor of 11.67 for the separation of $50 \% / 50 \% \mathrm{H}_{2} / \mathrm{CO}_{2}$ mixture.

In situ crystallization is a simple approach but multiple times of synthesis are typically required to ensure good membrane integrity. Therefore, surface modification of the support using covalent linkers (such as propyltriethoxysilane (APTES) [64,65], 3-(2-imidazolin-1-yl)propyltriethoxysilane 
(IPTES) [66] and polydopamine [67]) and $\mathrm{ZnO}[68,69]$ has been employed to promote local supersaturation and heterogeneous nucleation on the support surface. In particular, inspired by the bioadhesion ability of marine mussels, Caro and co-workers developed a versatile surface modification strategy using polydopamine as a covalent linker between the ZIF membrane and support [67]. Through simply immersing the support in a buffered aqueous dopamine solution $(\mathrm{pH}=8.5)$ for $20 \mathrm{~h}$ at room temperature, the polymerization of dopamine takes place spontaneously forming polydopamine which is simultaneously deposited on the support surface (Figure 4a-d). During the subsequent in situ synthesis, ZIF nutrients are attracted to the support surface forming strong covalent chemical bonds with polydopamine, thus significantly facilitating the nucleation and growth of uniform and continuous membranes. The resulting ZIF- 8 membrane has a thickness of $\sim 20 \mu \mathrm{m}$ and a $\mathrm{H}_{2} / \mathrm{C}_{3} \mathrm{H}_{8}$ selectivity of $\sim 700$ with a $\mathrm{H}_{2}$ permeance higher than $1.8 \times 10^{-7} \mathrm{~mol} \cdot \mathrm{Pa}^{-1} \cdot \mathrm{m}^{-2} \cdot \mathrm{s}^{-1}$. Surface functionalization can be applied to tubular supports as well [66,70,71]. For example, Tanaka et al. used IPTES to modify porous $\alpha$-alumina tubular supports [66], creating a pseudo-surface of ZIF-8 that contains imidazoline groups to coordinate with $\mathrm{Zn}$ acting as nucleation sites. The grain size within the resulting ZIF-8 membrane as well as the propylene/propane separation properties can be controlled by the graft density of IPTES.
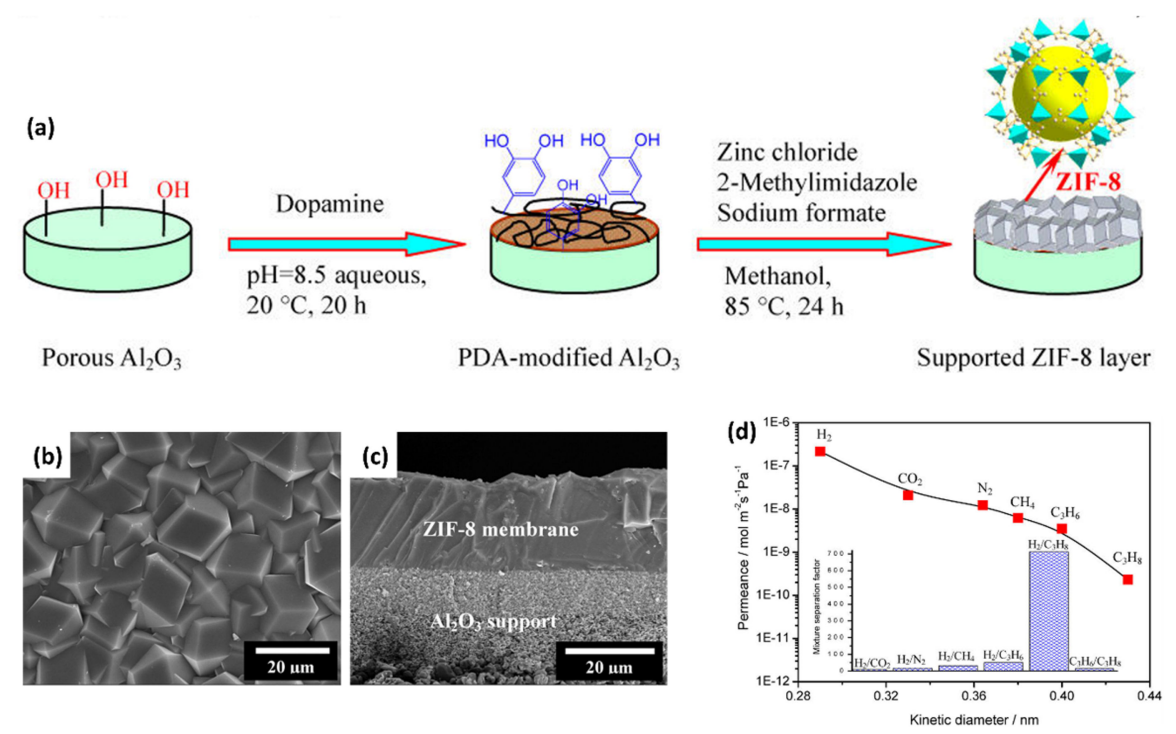

Figure 4. (a) Scheme of in situ synthesis of ZIF-8 membranes using dopamine as covalent linker between $\mathrm{ZIF}-8$ layer and $\mathrm{Al}_{2} \mathrm{O}_{3}$ support. (b) Top view and (c) cross-section SEM images of the ZIF-8 membrane. (d) Single gas permeances of different gases through the ZIF-8 membrane prepared on PDA-modified $\mathrm{Al}_{2} \mathrm{O}_{3}$ support at $150{ }^{\circ} \mathrm{C}$ as a function of kinetic diameter [67].

\subsubsection{Seeded Growth}

Compared to in situ synthesis, seeded growth offers a better control of the membrane formation and quality by decoupling the nucleation and growth steps. In this method, nanoscale ZIF crystals are first synthesized and coated on the surface of a support via different dip-coating, rubbing or directly synthesis techniques followed by hydro- or solvothermal synthesis to grow the seeds into a continuous thin film. ZIF-8 seed crystals with particle size smaller than $100 \mathrm{~nm}$ can be easily synthesized [72-74]. Heat treatment is sometimes employed to enhance the bonding between the support and the seeds layer. The secondary growth reported earlier was typically carried out through solvothermal synthesis at a temperature higher than $100{ }^{\circ} \mathrm{C}$ using DMF or methanol as the solvents. Lai and co-workers developed the synthesis of ZIF-8 crystals in aqueous solution [75,76], which is more environmental friendly and cost-effective. They later adapted the room temperature aqueous synthesis for the secondary growth of membranes, and prepared thin $(\sim 2 \mu \mathrm{m})$ ZIF- 8 membranes on alumina supports (Figure 5a-c) [61,77]. Because of the much reduced membrane thickness, their membranes showed a high hydrogen permeance up to $\sim 4 \times 10^{-7} \mathrm{~mol} \cdot \mathrm{Pa}^{-1} \cdot \mathrm{m}^{-2} \cdot \mathrm{s}^{-1}$. More importantly, the thin 
ZIF-8 membrane showed a propylene permeance of up to $2.06 \times 10^{-8} \mathrm{~mol} \cdot \mathrm{Pa}^{-1} \cdot \mathrm{m}^{-2} \cdot \mathrm{s}^{-1}$ and a propylene/propane separation factor up to 45 at $22{ }^{\circ} \mathrm{C}$. This was the first report of $\mathrm{C} 3$ separation using ZIF-8 membranes. The overall membrane performance in terms of mixture selectivity and propylene permeability (calculated from permeance and membrane thickness) have overcome the performance limits of polymer and CMS membranes (Figure 5c). Later, Liu et al. attempted to facilitate the membrane growth in aqueous solution by performing the synthesis at a higher temperature $\left(120{ }^{\circ} \mathrm{C}\right)$, and a mixture separation factor of $\sim 30$ was obtained [78]. In order to further improve the membrane reproducibility, Pan et al. introduced a methanol exchange step to replace the water molecules occluded inside the framework after membrane growth. Coupled with drying under saturated methanol pressure, the separation factor was dramatically enhanced from 31 to 89 [79]. Jeong and co-workers developed a microwave-assisted seeding method to enhance the interaction between the seeds and the substrate. Subsequent secondary growth of the seeds layers led to highly propylene-selective ZIF-8 membranes with an average propylene/propane selectivity of $\sim 40$ [80].

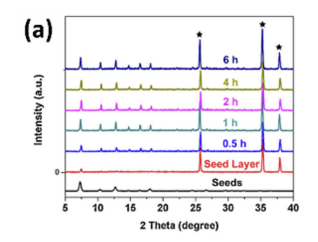

(b)
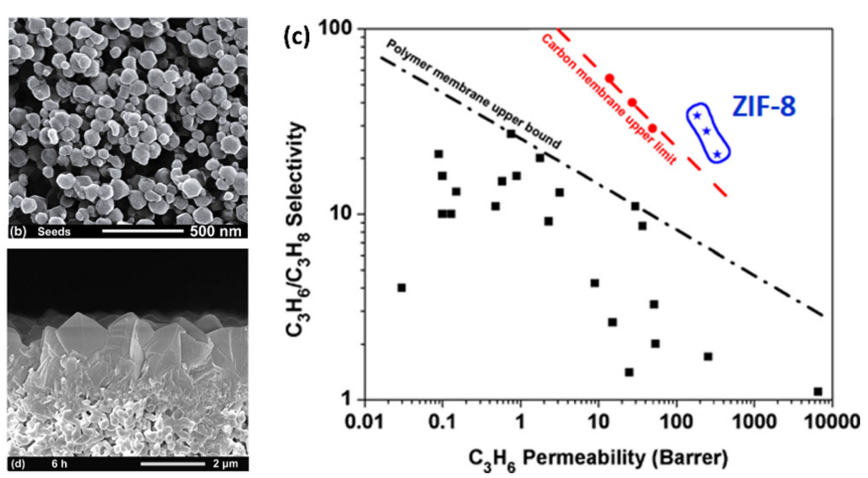

Figure 5. (a) XRD patterns of ZIF-8 seeds, seeded support and membranes grown at different conditions (Left), and SEM image of seeds (Right). (b) Top-view and cross-section SEM images of ZIF-8 membrane. (c) Propylene/propane separation performances in terms of selectivity and propylene permeability for polymer, carbon molecular sieve, and ZIF-8 membranes [61].

Seeded growth has also been used to prepare high quality ZIF-8 membranes on supports of different materials and geometries [69,80-83]. For example, Pan et al. reported the synthesis of $2 \mu \mathrm{m}$ thin ZIF-8 membranes on the outer surface of yttria-stabilized zirconia (YSZ) hollow fibers [84]. Due to the thin membrane thickness and low transport resistance of the hollow fiber support, the membranes showed a high hydrogen permeance of around $1.0 \times 10^{-6} \mathrm{~mol} \cdot \mathrm{Pa}^{-1} \cdot \mathrm{m}^{-2} \cdot \mathrm{s}^{-1}$ and a $\mathrm{H}_{2} / \mathrm{C}_{3} \mathrm{H}_{8}$ ideal selectivity above 500 . For the first time, Jin's group successfully prepared ZIF- 8 membrane on the inner surface of alumina hollow fiber supports using seeded growth method [85]. Unlike prior coating-based seeding techniques, the seeds layer in their work was directly synthesized on the inner surface of the fiber via flowing a seeding synthesis solution through the lumen of the hollow fiber. The secondary growth was performed in a similar manner but for an extended period of time.

\subsubsection{Counter-Diffusion Synthesis}

One unique property about the synthesis of ZIFs is the fast reaction between the metal and ligand precursors without the need of external structure directing agents (SDA). This allows the implementation of many new ideas to obtain membranes with even improved separation performance. One approach of particular interest is based on a counter-diffusion concept developed by Wang and Yao [86]. In their method, a nylon support was used to separate the zinc and linker solutions as shown in Figure 6a. Crystallization takes place once the precursor solutions diffuse through the support and react on both sides of the support. Synthesis conditions, including solution concentration and synthesis temperature, can be varied to tailor the membrane thickness and microstructure. This method enables the formation of a continuous ZIF-8 membrane on the zinc precursor side of the 
flexible nylon support. Jeong's group improved this method and developed an in situ synthesis approach based on the counter-diffusion concept [87]. In their method (Figure 6b), the porous alumina support is first soaked in the zinc salt solution and then transferred to the linker solution for solvothermal synthesis. During synthesis, the zinc ions diffuse from the support pores to the solution while the linkers diffuse in the opposite direction. They meet and react at the surface of the support, forming a continuous well-intergrown membrane. The prepared ZIF-8 membranes showed a high propylene/propane (50/50) mixture selectivity of $\sim 55$. The membranes also exhibited strong mechanical stability as evidenced by the almost unchanged separation performance after $2 \mathrm{~h}$ intensive sonication treatment. In addition, this method is capable of healing the defects in a poorly grown membrane and it can also be used to synthesize other types of membranes such as ZIF-7 and SIM-1 membranes [87]. In their following study, through optimizing the synthesis variables including the sodium formate to ligand ratio and the nature of the salts, the membrane separation factor was improved to 70 while maintaining a high propylene permeance of $2.68 \times 10^{-8} \mathrm{~mol} \cdot \mathrm{Pa}^{-1} \cdot \mathrm{m}^{-2} \cdot \mathrm{s}^{-1}$ [88]. This counter-diffusion in situ synthesis is a simple and versatile method that allows the rapid formation of well-intergrown ZIF-8 membranes with enhanced microstructure. This method has been adopted by other research groups $[89,90]$. For example, using a modified counter-diffusion approach, Hara and co-workers synthesized ZIF-8 membranes on a-alumina hollow capillary substrates for propylene/propane separation [90-92].

(a)
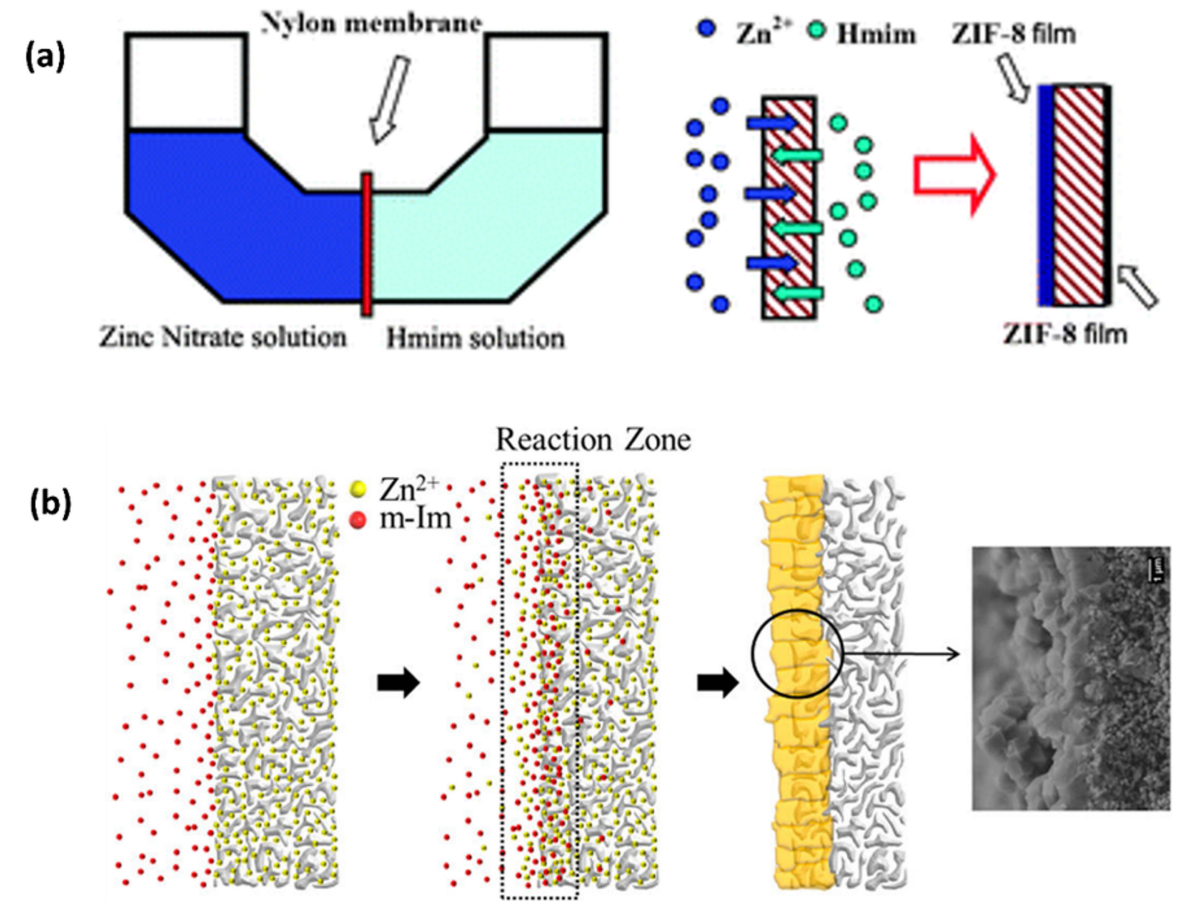

Figure 6. (a) Schematic of counter-diffusion synthesis of ZIF-8 membranes. The membranes form on both sides of the nylon support via counter-diffusion of $\mathrm{Zn}^{2+}$ and 2-methylimidazole through the pores of the nylon support [86]. (b) Scheme of the counter-diffusion-based in situ membrane synthesis method [87]: (1) A porous support pre-saturated with the zinc precursor is placed in the ligand solution containing sodium formate; (2) the diffusion of zinc ions and ligand molecules in the opposite directions forms a "reaction zone" near the support surface; and (3) rapid heterogeneous nucleation/crystal growth leads to a continuous membrane.

\subsubsection{Interfacial Microfluidic Processing}

Similar to zeolite membranes, most high quality ZIF membranes were prepared on ceramic substrates. Despite the excellent separation performance, high membrane cost imposed by the underlying ceramic support has hindered the industrial applications of ZIF membranes for gas 
separations. This issue can be addressed by replacing the ceramic support with more cost-effective and scalable polymer hollow fibers which can be processed into membrane module of high packing density. However, it was difficult to synthesize high quality ZIF membranes on polymer hollow fibers using the traditional in situ and seeded growth methods. In order to overcome this challenge, Nair, Jones, and co-workers developed an interfacial microfluidic membrane processing (IMMP) method that allows the fabrication and positional control of ZIF-8 membranes in polymeric hollow fibers [93]. In this method (Figure 7a-c), a dilute zinc nitrate hexahydrate/1-octanol solution was flowed through the bore of the fiber while a concentrated aqueous 2-methylimidazole (2-mIm) solution was present on the shell side. The membrane growth can be controlled by the flow conditions of the bore solutions. Highly intergrown ZIF-8 membranes were formed on the inner surface of the fiber when an initial continuous flow followed by static growth phases was used for the bore solution. This method has several important advantages including (1) in situ synthesis of ZIF membranes in the membrane module; (2) control of the membrane position through a two-solvent interfacial approach; and (3) controlled supply and replenishment of the reactants inside the hollow fiber bore using microfluidic technique. The mechanism and engineering of the interfacial microfluidic processing method was further investigated by Nair's and other research groups [94-98]. Under the optimized conditions, highly selective ZIF-8 membrane with a $\mathrm{C}_{3} \mathrm{H}_{6} / \mathrm{C}_{3} \mathrm{H}_{8}$ separation factor of 180 (at 1 bar and $25^{\circ} \mathrm{C}$ ) was achieved on poly(amide-imide) hollow fibers by the IMMP method [95]. Recently, through the combination of microwave assisted rapid-seeding and microfluidic secondary growth, Lee et al. fabricated ultrathin ZIF-8 membranes $(\sim 800 \mathrm{~nm})$ on either the bore or shell side of hollow fiber supports [99].

(a)

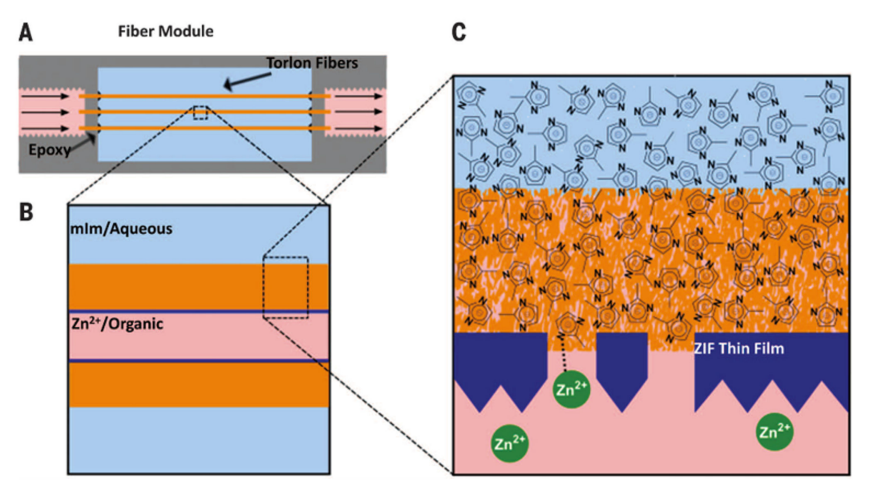

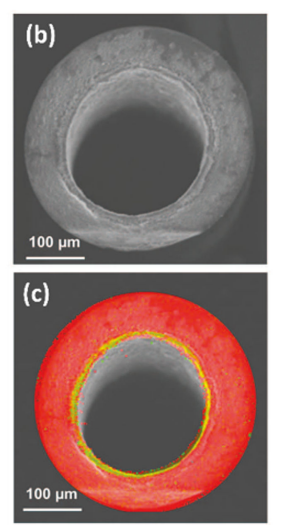

Figure 7. (a) Scheme showing the interfacial microfluidic membrane processing (IMMP) approach for ZIF membranes in hollow fibers. (b) Cross-section SEM and (c) EDX characterization of ZIF-8/hollow fiber membrane morphology and thickness. EDX elemental maps of carbon (red) and zinc (green) showing the localization of the ZIF-8 membrane on the inner surface of the fiber [93].

\subsubsection{Vapor-Phase Processing}

All the methods discussed above rely on solution-based processing steps, which are difficult to reliably scale up due to cost and environmental disadvantages [100-102]. For example, in most cases, large quantities of chemicals are required for the membrane synthesis because a significant amount of nutrients is consumed by the unavoidable homogeneous nucleation and growth of ZIFs in the liquid phase. In addition to increasing the membrane fabrication cost, the use of toxic solvents such as methanol and DMF in some processes also poses environmental risks. Therefore, replacing the hydrothermal or solvothermal synthesis with solution-free processing has cost and environmental advantages and are more promising for scale-up. The vapor-phase synthesis approach and its benefits have been demonstrated by zeolite membranes $[100,103,104]$. Recently, Stassen et al. reported a chemical vapor deposition process for the fabrication of ZIF thin films on silicon wafers for microelectronic applications [105]. This technique combines atomic layer deposition (ALD) of 
$\mathrm{ZnO}$ films and ligand vapor treatment using methylimidazole to partially convert the $\mathrm{ZnO}$ to ZIF-8. Inspired by this work, different groups have incorporated the concept of vapor-phase synthesis into the fabrication of ZIF membranes on porous substrates for separation applications $[101,102,106]$. Jeong's group developed a vapor-phase secondary growth method to fabricate thin ZIF-8 membranes supported on porous $\alpha$-alumina supports for propylene/propane separation [101]. In their method, a mixture of 2-methylimidazole and water vapors was used to treat a seeds layer of ZIF-8 crystals made by microwave synthesis. Upon vapor treatment, the crystals undergo an Ostwald-ripening-like process where bigger ZIF-8 crystals grow at the expense of smaller ones, forming a continuous thin film. One of the membranes prepared by this method exhibited a high propylene/propane separation factor of $\sim 120$. Later, Li et al. reported a gel-vapor deposition method for the production of ultrathin ZIF-8 membranes on polymeric hollow fiber supports [106]. A sol-gel method was used to deposit a Zn-based gel layer on ammoniated PVDF hollow fibers, followed by a ligand vapor treatment at $150{ }^{\circ} \mathrm{C}$ to convert the $\mathrm{Zn}$ gel to ZIF-8 layer. The resulting membrane exhibited a propylene permeance up to $2.8 \times 10^{-7} \mathrm{~mol} \cdot \mathrm{Pa}^{-1} \cdot \mathrm{m}^{-2} \cdot \mathrm{s}^{-1}$, the highest permeance reported for ZIF-8 membranes, while at the same time showing a high $\mathrm{C}_{3} \mathrm{H}_{6} / \mathrm{C}_{3} \mathrm{H}_{8}$ permselectivity of 67.2 .

More recently, Ma, Tsapatsis, and their colleagues developed an all-vapor-phase approach for the fabrication of high performance ZIF-8 membranes on $\alpha$-alumina macroporous substrate which has a $\sim 5 \mu \mathrm{m} \gamma$-alumina mesoporous layer coated on the surface [102]. Their method is based on the combination of the deposition of $\mathrm{ZnO}$ inside the support pores using ALD technique and a vapor ligand treatment to transform the $\mathrm{ZnO}$ deposits to a selective ZIF membrane (Figure 8a-d). During $\mathrm{ALD}$, the metal oxide precursor, diethylzinc reacts with the surface hydroxyl groups of the $\gamma$-alumina layer and the subsequent introduction of water vapor yields hydroxylated zinc oxide. After 10 ALD cycles, the $\mathrm{ZnO}$ deposits have almost completely blocked the 2-5 nm mesopores of the $\gamma$-alumina layer, resulting in an impermeable and nonselective $\mathrm{ZnO}$-alumina composite support (as shown in Figure 8c). After treatment of the support using 2-methylimidazole vapors generated by the sublimation of ligand powders, $\mathrm{ZnO}$ deposits were transformed to ZIF- 8 membranes that are highly selective and permeable to propylene (Figure $8 \mathrm{~d}$ ). The authors named this transformation process from a nonselective and impermeable deposit to a selective membrane as ligand-induced permselectivation (LIPS). In addition to the high propylene flux and high separation factor, the membranes prepared by LIPS also demonstrated stable performance in propylene/propane mixture separation tests under a feed pressure from 1 to $7 \mathrm{~atm}$. This new method has completely eliminated the use of solutions during membrane fabrication and is shown to be simple and highly reliable. It potentially can be used for the fabrication of other MOF and ZIF membranes. 
(a)

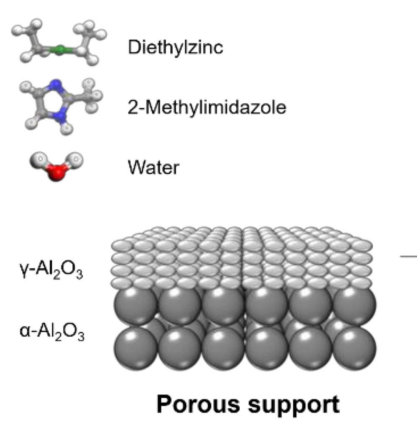

(c)

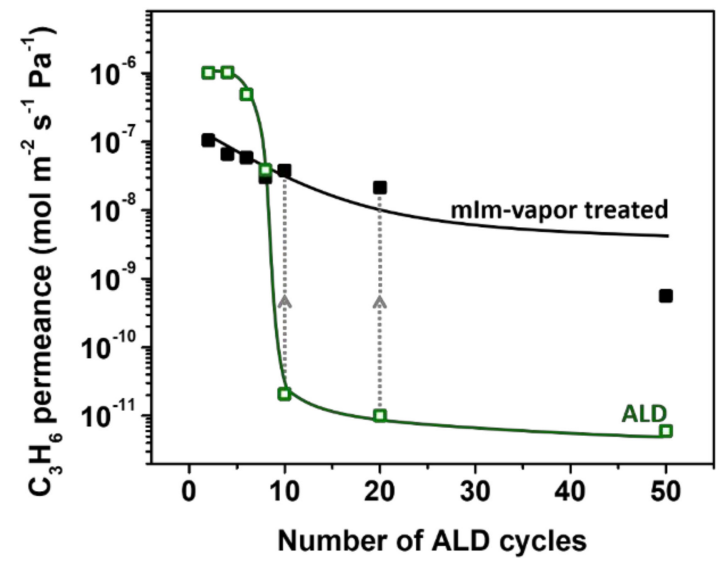

(b)

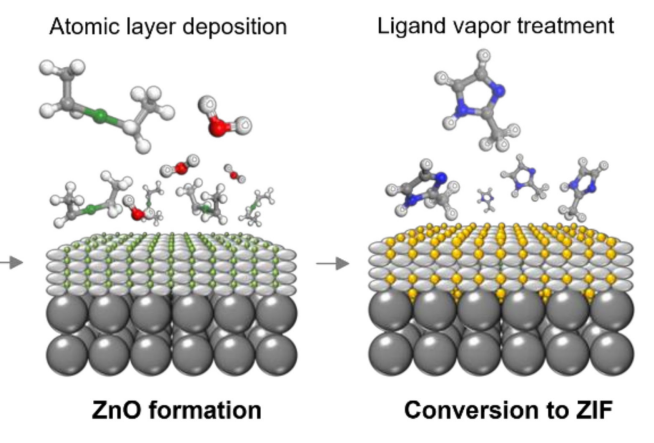

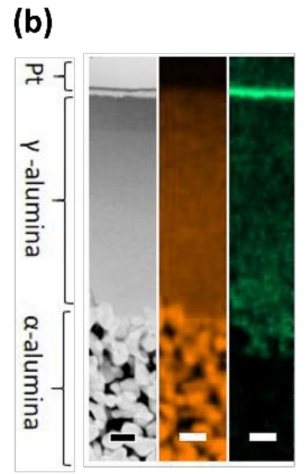

(d)

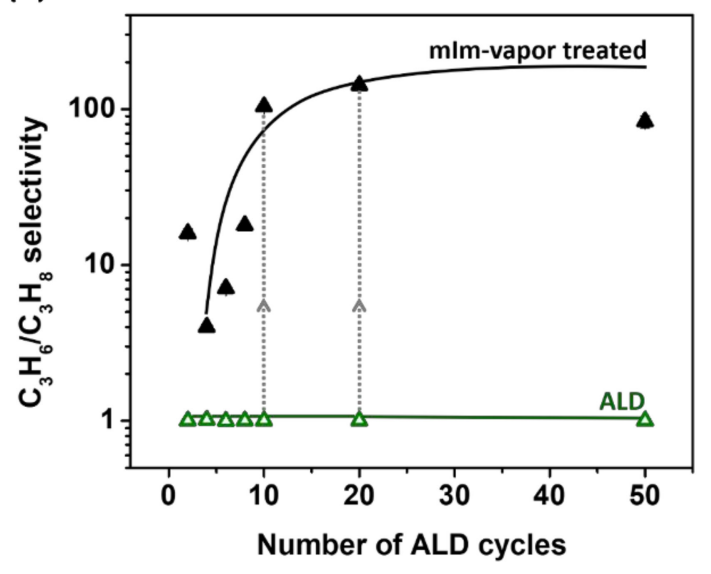

Figure 8. (a) Schematic of the all-vapor phase LIPS membrane fabrication process. (b) Cross section ADF-STEM image and corresponding spatial distribution of aluminum (orange) and zinc (green) for the ZIF-8 nanocomposite membrane. (c) Propylene permeance and (d) propylene/propane single component selectivities of the ALD treated support (green open symbols) and the corresponding ZIF-8 membranes (black solid symbols) as a function of the number of ALD cycles [102].

\subsubsection{Current-Driven Synthesis}

As discussed, the as-prepared ZIF-8 crystals via conventional hydrothermal synthesis possess intrinsic flexibility because of the linker mobility. It was suggested that ZIF-8 membrane performance can be improved by suppressing the linker motion [107]. Recently, Knebel, Caro, and co-workers reported that ZIF-8 structure can be transformed into polymorphs with more rigid lattices by applying an external electric field (E-field) [108]. Under E-filed, the ZIF-8 lattices are distorted from cubic (I-43m space group) to monoclinic ( $\mathrm{Cm}$ space group) and triclinic ( $\mathrm{R} 3 \mathrm{~m}$ space group) polymorphs, accompanied by the change of ZIF-8 pore diameter from 3.4 to 3.6 and $3.1 \AA$ (Figure 9a). Of particular interest is the $\mathrm{Cm}$ phase with strengthened framework and sharpened molecular sieving for propylene/propane separation. More recently, Wang's group developed an electrochemical method named "fast current driven synthesis" (FCDS) for the fabrication of ZIF-8 membranes on porous conductive supports (Figure $9 \mathrm{~b}$ ) [109]. It was revealed that approximately $60 \%$ to $70 \%$ of the ZIF-8 synthesized belongs to the ZIF-8_Cm polymorph with suppressed linker mobility. Hence, the membrane exhibited a dramatically enhanced propylene/propane separation factor up to 300 with a propylene permeance of $1.74 \times 10^{-8} \mathrm{~mol} \cdot \mathrm{Pa}^{-1} \cdot \mathrm{m}^{-2} \cdot \mathrm{s}^{-1}$. This method was then extended to prepare mixed-linker ZIF-7-8 membrane with improved molecular sieving capability for $\mathrm{CO}_{2} / \mathrm{CH}_{4}$ separation [110]. These results have demonstrated the great potential of the current-driven method. 
(a)

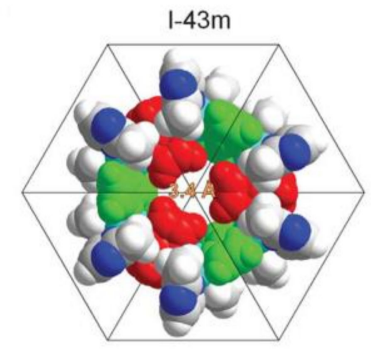

(b)
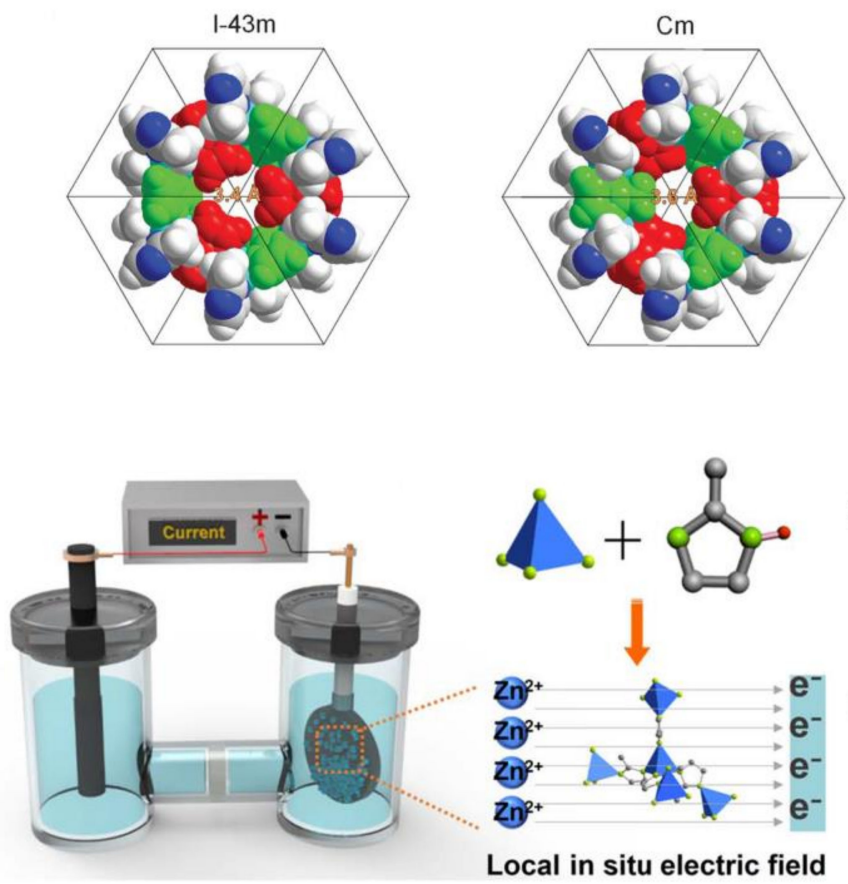
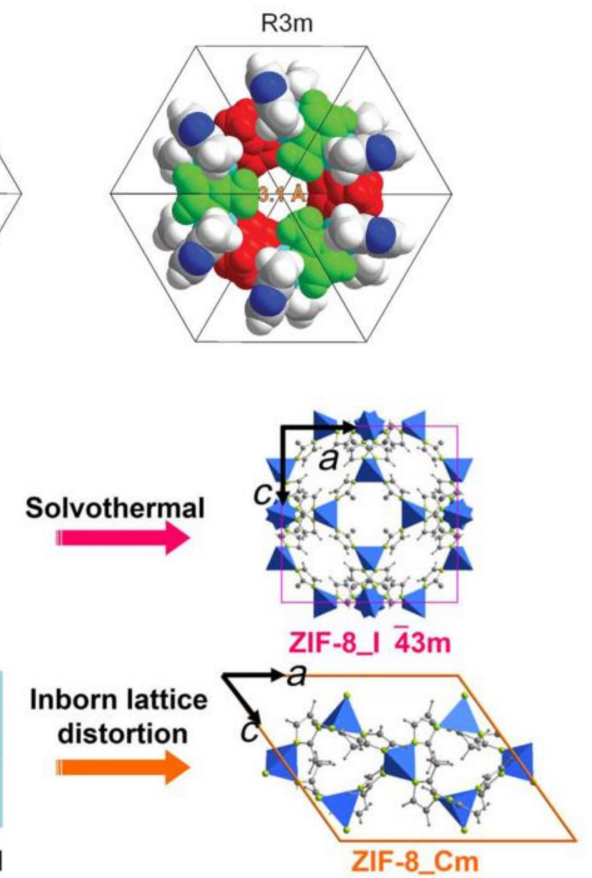

Figure 9. (a) The representation of the ZIF-8 gate as a space-filling model of the different simulated polymorphs [108]. (b) Schematic illustration of the ZIF-8 membrane growth by FCDS method in comparison with solvothermal growth. The support serves as a cathode in the electrochemcial system [109].

In summary, improving existing membrane synthesis methods and inventing new approaches are the most active topics in the field of ZIF membranes. As shown in Table 1, membranes made by in situ synthesis typically have a relatively large thickness and were mainly studied for hydrogen separations. Seeded growth has reduced the membrane thickness down to $\sim 2 \mu \mathrm{m}$ while simultaneously offering excellent propylene/propane separation properties. The separation performances were enhanced by emerging membrane synthesis methods, particularly the recently developed all-vapor ligand-induced permselectivation (LIPS) and fast current driven synthesis (FCDS). The full potential of these new approaches needs to be further exploited. On the other hand, each synthesis method involves many parameters (reaction temperature, time, reactant ratio, etc.) determining the membrane structure and property. It is a cumbersome but necessary task to comprehensively investigate their effects using the conventional approach by varying one parameter at a time. This limitation can be overcome by using a statistical approach based on design of experiments (DoE), in which all factors, randomization and replication of experiments are varied simultaneously [111-113]. In the field of membrane science $[113,114]$, DoE allows for the identification of the most relevant parameters and interactions affecting membrane synthesis with a reduced number of experiments. This powerful and efficient statistical approach should also be incorporated into the fabrication of ZIF membranes to facilitate the optimization of synthesis parameters to improve membrane performance and reduce production cost.

Table 1. Summary of membrane properties of representative ZIF membranes prepared by different methods.

\begin{tabular}{ccccccc}
\hline $\begin{array}{c}\text { Membrane Fabrication } \\
\text { Method }\end{array}$ & Support & $\begin{array}{c}\text { Membrane } \\
\text { Thickness }\end{array}$ & Gas Pair & $\begin{array}{c}\text { Permeance } \\
\left(\mathbf{m o l} \cdot \mathbf{m}^{-2} \cdot \mathbf{s}^{-\mathbf{1}} \cdot \mathbf{P a}^{-\mathbf{1}}\right)\end{array}$ & $\begin{array}{c}\text { Separation } \\
\text { Factor }\end{array}$ & $\begin{array}{c}\text { REF } \\
\end{array}$ \\
\cline { 2 - 7 } & Titania support & $\sim 30 \mu \mathrm{m}$ & $\mathrm{H}_{2} / \mathrm{CH}_{4}$ & $5.08 \times 10^{-8}\left(\mathrm{H}_{2}\right)$ & 11.2 & {$[60]$} \\
\cline { 2 - 8 } In situ synthesis & $\mathrm{Al}_{2} \mathrm{O}_{3}$ support & $\sim 20 \mu \mathrm{m}$ & $\mathrm{H}_{2} / \mathrm{C}_{3} \mathrm{H}_{8}$ & $1.8 \times 10^{-7}\left(\mathrm{H}_{2}\right)$ & 712.6 & {$[67]$} \\
\cline { 2 - 8 } & $\begin{array}{c}\text { Macroporous } \\
\mathrm{Al}_{2} \mathrm{O}_{3} \text { tube }\end{array}$ & $25 \mu \mathrm{m}$ & $\mathrm{H}_{2} / \mathrm{C}_{3} \mathrm{H}_{8}$ & $1.1 \times 10^{-7}\left(\mathrm{H}_{2}\right)$ & 328.6 & {$[71]$} \\
\cline { 2 - 7 } & $\mathrm{Si}_{3} \mathrm{~N}_{4}$ hollow fiber & $\sim 30 \mu \mathrm{m}$ & $\mathrm{H}_{2} / \mathrm{CO}_{2}$ & $8.35 \times 10^{-7}\left(\mathrm{H}_{2}\right)$ & 11.7 & {$[63]$} \\
\hline
\end{tabular}


Table 1. Cont.

\begin{tabular}{|c|c|c|c|c|c|c|}
\hline $\begin{array}{c}\text { Membrane Fabrication } \\
\text { Method }\end{array}$ & Support & $\begin{array}{l}\text { Membrane } \\
\text { Thickness }\end{array}$ & Gas Pair & $\begin{array}{c}\text { Permeance } \\
\left(\mathrm{mol} \cdot \mathrm{m}^{-2} \cdot \mathrm{s}^{-1} \cdot \mathrm{Pa}^{-1}\right)\end{array}$ & $\begin{array}{l}\text { Separation } \\
\text { Factor }\end{array}$ & REF \\
\hline \multirow{8}{*}{ Seeded growth } & \multirow{2}{*}{$\alpha-\mathrm{Al}_{2} \mathrm{O}_{3}$ support } & \multirow{2}{*}{$\sim 2.2 \mu \mathrm{m}$} & \multirow{2}{*}{$\mathrm{C}_{3} \mathrm{H}_{6} / \mathrm{C}_{3} \mathrm{H}_{8}$} & $2.06 \times 10^{-8}\left(\mathrm{C}_{3} \mathrm{H}_{6}\right)$ & 45 & \multirow{2}{*}{ [61] } \\
\hline & & & & $2.77 \times 10^{-8}\left(\mathrm{C}_{3} \mathrm{H}_{6}\right)$ & 35 & \\
\hline & \multirow{2}{*}{$\alpha-\mathrm{Al}_{2} \mathrm{O}_{3}$ support } & \multirow{2}{*}{$\sim 0.5-1.6 \mu \mathrm{m}$} & \multirow{2}{*}{$\mathrm{C}_{3} \mathrm{H}_{6} / \mathrm{C}_{3} \mathrm{H}_{8}$} & $7.8 \times 10^{-9}\left(\mathrm{C}_{3} \mathrm{H}_{6}\right)$ & 89 & \multirow{2}{*}{ [79] } \\
\hline & & & & $1.56 \times 10^{-8}\left(\mathrm{C}_{3} \mathrm{H}_{6}\right)$ & 50 & \\
\hline & $\alpha-\mathrm{Al}_{2} \mathrm{O}_{3}$ support & $\sim 1.5 \mu \mathrm{m}$ & $\mathrm{C}_{3} \mathrm{H}_{6} / \mathrm{C}_{3} \mathrm{H}_{8}$ & $2.08 \times 10^{-8}\left(\mathrm{C}_{3} \mathrm{H}_{6}\right)$ & 40 & [80] \\
\hline & $\begin{array}{l}\text { Commercial } \\
\text { ceramic tube }\end{array}$ & $\sim 1.2 \mu \mathrm{m}$ & $\mathrm{C}_{3} \mathrm{H}_{6} / \mathrm{C}_{3} \mathrm{H}_{8}$ & $1.90 \times 10^{-8}\left(\mathrm{C}_{3} \mathrm{H}_{6}\right)$ & 80 & [82] \\
\hline & YSZ hollow fiber & $\sim 2 \mu \mathrm{m}$ & $\mathrm{H}_{2} / \mathrm{C}_{3} \mathrm{H}_{8}$ & $1.50 \times 10^{-6}\left(\mathrm{H}_{2}\right)$ & $>1000$ & [84] \\
\hline & $\begin{array}{l}\alpha-\mathrm{Al}_{2} \mathrm{O}_{3} \text { hollow } \\
\text { fiber }\end{array}$ & $\sim 2 \mu \mathrm{m}$ & $\mathrm{H}_{2} / \mathrm{CO}_{2}$ & $\sim 4 \times 10^{-7}\left(\mathrm{H}_{2}\right)$ & 3.28 & [85] \\
\hline \multirow{5}{*}{ Counter diffusion } & Nylon support & $\sim 16 \mu \mathrm{m}$ & $\mathrm{H}_{2} / \mathrm{N}_{2}$ & $1.97 \times 10^{-6}\left(\mathrm{H}_{2}\right)$ & 4.3 & [86] \\
\hline & $\alpha-\mathrm{Al}_{2} \mathrm{O}_{3}$ support & $\sim 1.5 \mu \mathrm{m}$ & $\mathrm{C}_{3} \mathrm{H}_{6} / \mathrm{C}_{3} \mathrm{H}_{8}$ & $2.13 \times 10^{-8}\left(\mathrm{C}_{3} \mathrm{H}_{6}\right)$ & 50 & [87] \\
\hline & $\alpha-\mathrm{Al}_{2} \mathrm{O}_{3}$ support & $1 \mu \mathrm{m}$ & $\mathrm{C}_{3} \mathrm{H}_{6} / \mathrm{C}_{3} \mathrm{H}_{8}$ & $2.68 \times 10^{-8}\left(\mathrm{C}_{3} \mathrm{H}_{6}\right)$ & 70.6 & [88] \\
\hline & $\begin{array}{c}\alpha-\mathrm{Al}_{2} \mathrm{O}_{3} \text { hollow } \\
\text { capillary substrate }\end{array}$ & $20 \mu \mathrm{m}$ & $\mathrm{C}_{3} \mathrm{H}_{6} / \mathrm{C}_{3} \mathrm{H}_{8}$ & $1.2 \times 10^{-8}\left(\mathrm{C}_{3} \mathrm{H}_{6}\right)$ & 20 & [90] \\
\hline & $\begin{array}{c}\alpha-\mathrm{Al}_{2} \mathrm{O}_{3} \text { hollow } \\
\text { capillary substrate }\end{array}$ & $40-50 \mu \mathrm{m}$ & $\mathrm{C}_{3} \mathrm{H}_{6} / \mathrm{C}_{3} \mathrm{H}_{8}$ & $2.2 \times 10^{-9}\left(\mathrm{C}_{3} \mathrm{H}_{6}\right)$ & 10 & [92] \\
\hline \multirow{4}{*}{$\begin{array}{l}\text { Interfacial microfluidic } \\
\text { processing }\end{array}$} & $\begin{array}{c}\text { Polymer } \\
\text { hollow fiber }\end{array}$ & $\sim 8.8 \mu \mathrm{m}$ & $\mathrm{C}_{3} \mathrm{H}_{6} / \mathrm{C}_{3} \mathrm{H}_{8}$ & $9 \times 10^{-9}\left(\mathrm{C}_{3} \mathrm{H}_{6}\right)$ & 12 & [93] \\
\hline & $\begin{array}{l}\text { Polymer } \\
\text { hollow fiber }\end{array}$ & $\sim 8 \mu \mathrm{m}$ & $\mathrm{C}_{3} \mathrm{H}_{6} / \mathrm{C}_{3} \mathrm{H}_{8}$ & $1.51 \times 10^{-8}\left(\mathrm{C}_{3} \mathrm{H}_{6}\right)$ & 184.4 & [94] \\
\hline & $\begin{array}{c}\text { Polymer } \\
\text { hollow fiber }\end{array}$ & $5 \mu \mathrm{m}$ & $\mathrm{C}_{3} \mathrm{H}_{6} / \mathrm{C}_{3} \mathrm{H}_{8}$ & $2.21 \times 10^{-8}\left(\mathrm{C}_{3} \mathrm{H}_{6}\right)$ & 65 & [95] \\
\hline & $\begin{array}{c}\text { Polymer } \\
\text { hollow fiber }\end{array}$ & $8.5 \mu \mathrm{m}$ & $\mathrm{CO}_{2} / \mathrm{N}_{2}$ & $7.4 \times 10^{-9}\left(\mathrm{CO}_{2}\right)$ & 52 & [98] \\
\hline Vapor-phase ripening & $\alpha-\mathrm{Al}_{2} \mathrm{O}_{3}$ support & $300-400 \mathrm{~nm}$ & $\mathrm{C}_{3} \mathrm{H}_{6} / \mathrm{C}_{3} \mathrm{H}_{8}$ & $1.25 \times 10^{-8}\left(\mathrm{C}_{3} \mathrm{H}_{6}\right)$ & 120 & [101] \\
\hline Gel-vapor deposition & PVDF hollow fiber & $<20 \mathrm{~nm}$ & $\mathrm{C}_{3} \mathrm{H}_{6} / \mathrm{C}_{3} \mathrm{H}_{8}$ & $2.8 \times 10^{-7}\left(\mathrm{C}_{3} \mathrm{H}_{6}\right)$ & 67.2 & [106] \\
\hline \multirow{2}{*}{$\begin{array}{l}\text { All-vapor ligand-induced } \\
\text { permselectivation }\end{array}$} & \multirow{2}{*}{$\begin{array}{c}\gamma-\mathrm{Al}_{2} \mathrm{O}_{3} \text { coated } \\
\alpha-\mathrm{Al}_{2} \mathrm{O}_{3} \text { support }\end{array}$} & \multirow{2}{*}{$<500 \mathrm{~nm}$} & \multirow{2}{*}{$\mathrm{C}_{3} \mathrm{H}_{6} / \mathrm{C}_{3} \mathrm{H}_{8}$} & $8.8 \times 10^{-8}\left(\mathrm{C}_{3} \mathrm{H}_{6}\right)$ & 71 & \multirow[t]{2}{*}{ [102] } \\
\hline & & & & $1.6 \times 10^{-7}\left(\mathrm{C}_{3} \mathrm{H}_{6}\right)$ & 74 & \\
\hline Current-driven synthesis & $\begin{array}{c}\text { Pt coated } \\
\text { AAO support }\end{array}$ & $\sim 200 \mathrm{~nm}$ & $\mathrm{C}_{3} \mathrm{H}_{6} / \mathrm{C}_{3} \mathrm{H}_{8}$ & $1.74 \times 10^{-8}\left(\mathrm{C}_{3} \mathrm{H}_{6}\right)$ & 300 & [109] \\
\hline $\begin{array}{c}\text { Postsynthetic } \\
\text { linker exchange }\end{array}$ & $\alpha-\mathrm{Al}_{2} \mathrm{O}_{3}$ support & $<1 \mu \mathrm{m}$ & $\mathrm{C}_{3} \mathrm{H}_{6} / \mathrm{C}_{3} \mathrm{H}_{8}$ & $7.8 \times 10^{-8}\left(\mathrm{C}_{3} \mathrm{H}_{6}\right)$ & 40 & [115] \\
\hline
\end{tabular}

\subsection{ZIF-8 Membranes for C3 Separation: Permeation Characteristic and Stability}

In most studies, membrane permeance and selectivity/separation factor were measured at room temperature using Wicke-Kallenbach method, in which a 50/50 propylene/propane mixture is used on the feed side with the permeate side swept by $1 \mathrm{~atm}$ inert gas such as $\mathrm{Ar}, \mathrm{He}$ or $\mathrm{N}_{2}$ [61]. This standard measurement has facilitated the performance comparison between membranes made by different research groups. However, membrane separations in industry are typically performed at more complex conditions under different temperatures, feed pressures, feed compositions and with no sweep on the permeate. For example, propylene/propane separation is often operated on the output of refinery steam crackers or on petrochemical purge streams, both of which are typically at elevated pressures (100-150 psia) [116]. On the other hand, increasing the feed pressure in membrane separation process will increase the pressure ratio (the ratio of feed to permeate pressures) which usually leads to a much higher flux and a significant reduction of the required membrane area $[117,118]$. Another membrane characteristic required for practical application is the long-term membrane stability. Therefore, it is of practical importance to investigate the propylene/propane separation performance under different operation conditions, especially under high feed pressure, as well as evaluate the stability of membrane performance under continuous separation.

Lai's group studied the feed composition (or propylene fraction in the feed) and temperature dependency of propylene/propane separation for ZIF-8 membranes prepared on alumina supports [61]. Atmosphere pressure was applied to both sides of the membrane and helium was used as sweep 
gas. In a wide temperature range from $-15^{\circ} \mathrm{C}$ to $180^{\circ} \mathrm{C}$ as shown in Figure $10 \mathrm{a}$, both propylene permeance and propylene/propane separation factor decreased as the increase of temperature. Liu et al. systematically investigated the propylene/propane permeation and separation characteristics of ZIF-8 membranes in comparison with the gas transport properties of ZIF-8 crystals [78]. Similar temperature dependence was observed for single component permeance of propylene and propylene/propane perm-selectivity (Figure 10b). The temperature dependence observed by these two groups is consistent with the combined effects of temperature on the adsorption and diffusion of the gas molecules for ZIF-8 membrane. The heat of adsorption for propylene $(30 \mathrm{~kJ} / \mathrm{mol})$ is higher than the activation energy of diffusion $(9.7 \mathrm{~kJ} / \mathrm{mol})$, while for propane the heat of adsorption $(34 \mathrm{~kJ} / \mathrm{mol})$ is smaller than the activation energy of diffusion $(74.1 \mathrm{~kJ} / \mathrm{mol})$ [51]. Consequently, propylene permeance decreases with increasing temperature while propane permeance shows an opposite dependence, resulting in a decreasing selectivity.
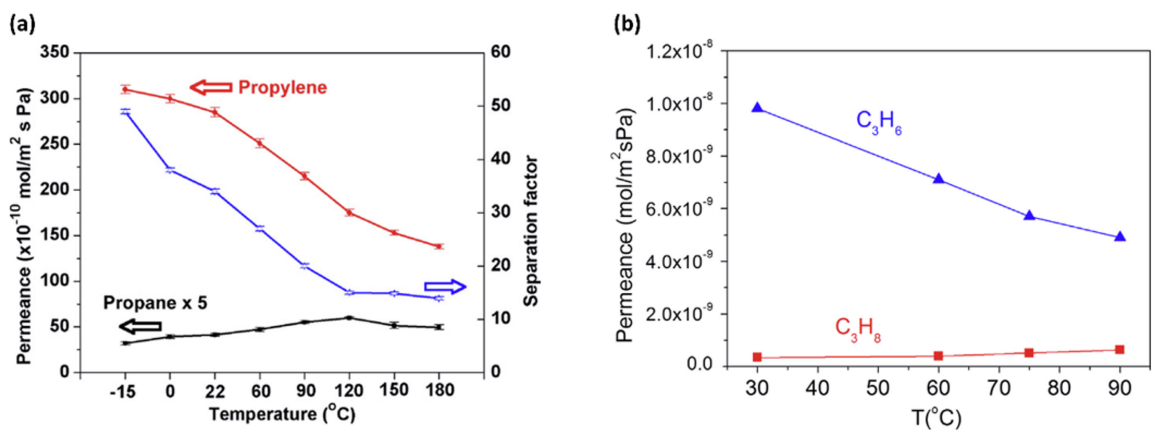

Figure 10. (a) Temperature dependence of permeances and propylene/propane mixture separation factor for ZIF-8 membrane [61]. (b) Temperature dependence of single gas permeances of propylene and propane for ZIF-8 membrane [78].

Changes in feed pressure and feed composition affect the adsorption properties (solubility) of the gas molecules in the membrane. In the study on the pressure dependence in a range from $1 \mathrm{~atm}$ to $\sim 5$ atm for a high quality ZIF- 8 membrane prepared by secondary growth, the permeances for propylene and propane and the propylene/propane selectivity decrease with the increasing feed pressure in both single component and mixed gas permeation tests [78]. The change of permeances can be explained by the non-linear (Langmuir) adsorption isotherms reported for both molecules on ZIF-8 crystals [51,52]. Yu et al. also reported a $\sim 30 \%$ decrease in propylene permeance and a large reduction of propylene/propane separation factor from 61 to 14 as the feed pressure was varied from $1 \mathrm{~atm}$ to 4 atm [68]. Even for a highly selective polymer hollow fiber supported ZIF-8 membrane prepared by Nair's group, the separation factor dropped from $\sim 180$ to $\sim 90$ as the total transmembrane pressure difference increased from 1 bar to 8.5 bar [94]. Similar pressure dependence of selectivity has also been reported by other groups, regardless of the different membrane quality, membrane preparation methods and supports used in these studies [106]. Since many of these membranes are of high quality with a separation factor above 50 , the effect of defects on the selectivity can be excluded. Therefore, the decreasing selectivity as increasing feed pressure is most likely due to the pressure effects on adsorption isotherm and/or decreased diffusion selectivity caused by the structural flexibility of ZIF-8. Despite possessing the zeolite-like topology, there is increasing evidence that even at room temperature the aperture size of ZIFs could be affected by the rotation of ligands [56,57]. As a result, the effective aperture size of the 6-ring window in ZIF-8 for molecular sieving is determined to be $\sim 4.0-4.2 \AA$, significantly larger than the value of $3.4 \AA$ obtained from single-crystal XRD [52]. At a high feed pressure, the increasing loading of propylene and propane in the framework might further enlarge the effective aperture size, decreasing the diffusion selectivity for propylene/propane. However, the separation factor of the ZIF-8 membrane fabricated by the LIPS method stayed almost unchanged ( 70) with the feed pressure increasing up to 7 bar [102]. This could be attributed to the improved 
microstructure of the ZIF-8 membrane which is partly present on the external surface of the support and partly confined in the support pores.

Long-term membrane stability under continuous operation is of practical importance [119]. Compared to many MOFs reported earlier, ZIFs in general possess improved chemical and thermal stability due to the strong bonds in their zeolite-like structure. However, recent studies have found that ZIF membrane, a thin film form of well-intergrown ZIFs, experienced certain degree of structural degradation during gas separation above ambient temperature and liquid separations involving water [120-123]. For the separation of dry propylene/propane mixture at room temperature, excellent stability has been demonstrated by different groups. For example, Eum et al. reported stable permeances and separation factors for 30 days for continuous separation of an equimolar binary $\mathrm{C}_{3} \mathrm{H}_{6} / \mathrm{C}_{3} \mathrm{H}_{8}$ feed at $25^{\circ} \mathrm{C}$ and 1 bar feed pressure (Figure 11a) [94]. Liu et al. have also shown that ZIF-8 membranes are stable under both on-stream propylene/propane separation and off-stream storage conditions [78]. More recently, stable propylene/propane separation performance in mixed gas separation tests under high feed pressure was demonstrated on the membranes made by LIPS method (Figure 11b) [102]. Despite the adequate stability demonstrated in laboratories, more studies on membrane stability, especially under the presence of impurities in industrial gas stream such as water vapor and $\mathrm{H}_{2} \mathrm{~S}$, are still needed.
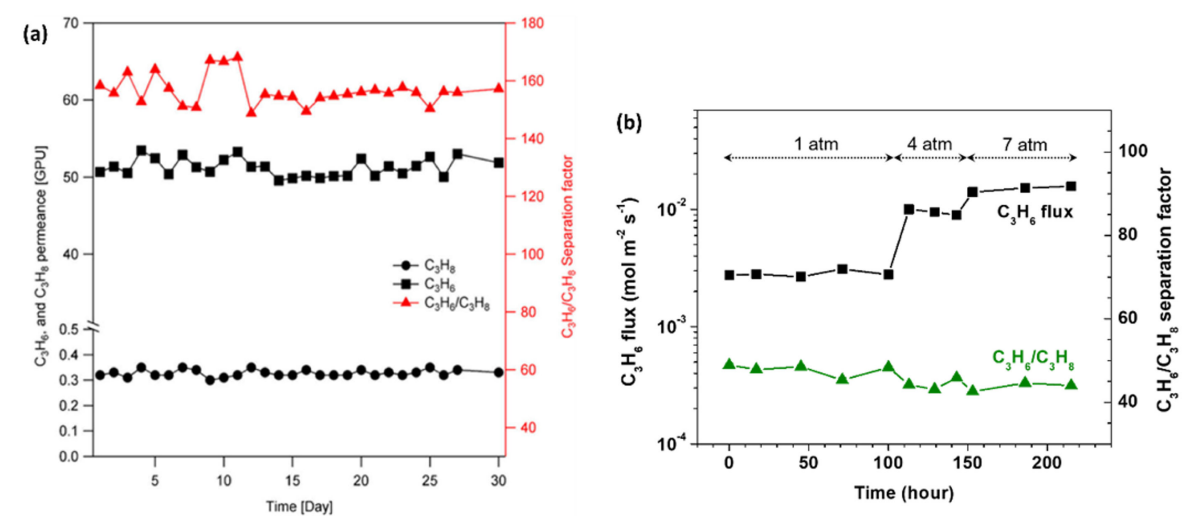

Figure 11. On-stream stability of $\mathrm{C}_{3} \mathrm{H}_{6} / \mathrm{C}_{3} \mathrm{H}_{8}$ mixture separation performance. (a) Stability of a ZIF-8 hollow fiber membrane operated continuously for 30 days under an equimolar $\mathrm{C}_{3} \mathrm{H}_{6} / \mathrm{C}_{3} \mathrm{H}_{8}$ mixture feed at $25^{\circ} \mathrm{C}$ and 1 bar feed pressure [94]. (b) Stability of a ZIF- 8 membrane made by LIPS method tested at room temperature with an equimolar $\mathrm{C}_{3} \mathrm{H}_{6} / \mathrm{C}_{3} \mathrm{H}_{8}$ mixture feed under different pressures from $1 \mathrm{~atm}$ to $\sim 7 \mathrm{~atm}[102]$.

\subsection{Other ZIF Membranes for C3 Separation}

Although ZIF-8 remains the most studied ZIFs for propylene/propane separation, it was discovered by Jeong's group that ZIF-67 (Co-substituted ZIF-8) membranes outperformed almost all previously reported ZIF-8 membranes [124]. Three types of ZIF-67 membranes were synthesized in their work: (1) Pure ZIF-67 membranes exhibited an average propylene/propane separation factor of 85; (2) ZIF-8/ZIF-67 composite membranes made by tertiary growth showed an unprecedentedly high separation factor of $~ 190$; and (3) ZIF-67 / ZIF-67 bilayer membranes are also highly selective with a mixture separation factor of $\sim 160$. On the other hand, the propylene permeability of ZIF-67 is similar to that of ZIF-8 membranes. As evidenced by the high selectivities, ZIF-67 might be inherently more selective to propylene over propane than ZIF-8. A blue shift was observed in the IR band associated with the Co-N stretching frequency in ZIF-67 as compared to Zn-N in ZIF-8, implying that Co-N bonds are more rigid than $\mathrm{Zn}-\mathrm{N}$ bonds. NMR spectra also suggested that $\mathrm{Co}-\mathrm{N}$ bonds are more ionic and thus stiffer than $\mathrm{Zn}-\mathrm{N}$ bonds, consistent with the IR results. Therefore, it was hypothesized by Jeong and co-workers that the rigid Co-N connectivity could restrict the degree of ligand flipping motion, thus leading to slightly smaller effective aperture size and consequently higher selectivity. Their hypothesis was supported by molecular simulations which showed a dramatic increase of 
propylene/propane corrected diffusivities ratio as compared to ZIF-8 [125]. The combination of experimental and computational results suggested that ZIF-67 framework is a promising new candidate for propylene/propane separation.

ZIF membrane containing mixed linkers is a new type of membrane for propylene/propane separation [115]. In an effort to enhance the membrane permeance, Jeong's group performed partial exchange of the 2-methylimidazole ligand in the ZIF-8 membrane top layer with imidazolecarboxaldehyde (Ica, ZIF-90 linker) via postsynthetic ligand exchange (PSLE) [115]. The top Ica-exchanged ZIF layer can lead to a reduction in the effective thickness of ZIF-8 membrane, thus resulting in a 4-times increase in the propylene permeance $\left(7.80 \times 10^{-8} \mathrm{~mol} \cdot \mathrm{Pa}^{-1} \cdot \mathrm{m}^{-2} \cdot \mathrm{s}^{-1}\right)$ with only a small loss in the separation factor (Figure 12a,b).
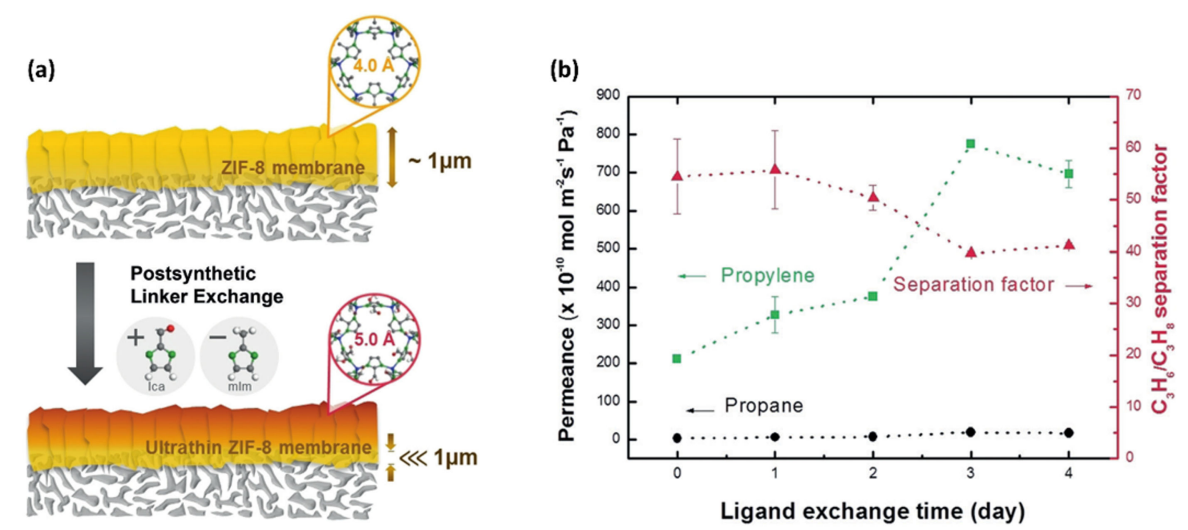

Figure 12. (a) Illustration of the postsynthetic ligand exchange of mIm (ZIF-8 linker) of ZIF-8 membranes with Ica (ZIF-90 linker). (b) Binary propylene/propane separation performances of ZIF-8 membranes postsynthetically linker exchanged with Ica for different reaction times [115].

\section{ZIF Membranes for Ethylene/Ethane Separation}

Enriching ethylene from ethylene/ethane mixtures is one of the most challenging separations in industry. Most membranes cannot achieve the productivity (permeability), efficiency (selectivity) and stability combinations required for $\mathrm{C} 2$ separation. Among the materials that has been explored, Koros identified carbon molecular sieve (CMS) membranes as a promising candidate for $\mathrm{C} 2$ separation as evidenced by their superior separation performance above the polymeric upper bound as well as good membrane processability [4]. Considering the high tunability of the membrane structure, ZIF membranes may provide another attractive alternative. However, there are only a limited number of studies on C2 separation using ZIF membranes, and the performances achieved thus far are rather moderate.

\subsection{ZIF-8 Membranes for C2 Separation}

ZIF-8 membranes have been shown to be highly selective for propylene over propane, but their ethylene/ethane separation capability is quite limited. Caro and co-workers studied the ethylene/ethane separation properties of a $25 \mu \mathrm{m}$ thick ZIF-8 membrane prepared on asymmetric titania support [126]. A moderate separation factor of 4.2 and $~ 2.5$ were observed in single component and mixed gas permeation tests, respectively. These values are slightly larger than the membrane selectivities predicted from the adsorption and diffusion selectivity based on adsorption uptake measurements on large ZIF-8 single crystals. Based on gas permeation measurements and isotherm data, Pan et al. obtained the thermodynamically corrected diffusivities of light hydrocarbons and the ethylene/ethane diffusivity selectivity was calculated to be $\sim 8$ [126]. Lin's group systematically studied the ethylene/ethane transport characteristics of ZIF-8 membranes in single and binary gas mixtures under different conditions [127]. The ethane/ethane selectivities are between 1.5 and 3 under all testing conditions. In the temperature range from $25^{\circ} \mathrm{C}$ to $100{ }^{\circ} \mathrm{C}$, the permeances of ethylene 
and ethane decreased as the increase of temperature because the activation energies of diffusion for ethylene and ethane (11.7 and $13.2 \mathrm{~kJ} / \mathrm{mol}$ ) are lower than their respective heats of adsorption (16.2 and $17.1 \mathrm{~kJ} / \mathrm{mol})$. In the pressure dependence tests, $\mathrm{C} 2$ ideal selectivity increases with pressure while the binary separation factor decreases due to the different isotherms for single gas and binary $\mathrm{C} 2$ adsorption. The low membrane selectivity observed for ZIF-8 membranes in these studies can be explained by the low diffusive selectivity offered by the $4.0-4.2 \AA$ pore window of ZIF- 8 which is larger than the molecular diameters of $\mathrm{C} 2$ molecules (van der Waals diameters: ethylene $=3.59 \AA$, ethane $=3.72 \AA$ ).

\subsection{ZIF-7 Membranes for C2 Separation}

It can be expected that a slight reduction in the ZIF-8 pore size could lead to improved molecular sieving for ethylene and ethane. Hence, ZIF-7 is potentially a good candidate for C2 separation. ZIF-7 also possesses a SOD topology and is constructed by zinc ions linked by benzimidzole (bIM) ligands. The bulky benzene rings in the ligand narrows the crystallographic aperture size of ZIF-7 to $\sim 3 \AA$, slightly smaller than that of ZIF-8 ( 3.4 $⿱$ ). Synthesis of high quality ZIF-7 membranes has been well documented. ZIF-7 membranes were first synthesized on alumina supports by Li, Caro, and their co-workers using a microwave-assisted secondary growth technique (Figure 13a-c) [128]. In binary mixture separations, the membrane exhibited a $\mathrm{H}_{2} / \mathrm{N}_{2}$ and $\mathrm{H}_{2} / \mathrm{CH}_{4}$ separation factor of 7.7 and 5.9, respectively (at $200{ }^{\circ} \mathrm{C}$ and 1 bar feed pressure), both are higher than their corresponding Knudsen selectivities (3.7 and 2.8, respectively). In their following study, ZIF-7 membrane exhibited a high $\mathrm{H}_{2} / \mathrm{CO}_{2}$ mixture separation factor of $\sim 13$ at $220{ }^{\circ} \mathrm{C}$ and excellent hydrothermal stability in the presence of steam, demonstrating great potential for hydrogen production and recycling applications such as water-gas shift membrane reactor [129]. In order to address the drawbacks of low reproducibility and scalability, Kim's group developed a novel direct spraying approach for the synthesis of well-intergrown ZIF-7 membranes in a facile and time efficient ( $<20 \mathrm{~min}$ ) manner [130]. Their method is based on the electrostatic force-assisted spraying to deposit fine liquid droplets of ZIF-7 precursors on the surface of heated alumina supports, directly forming a membrane layer. The membrane thickness can be controlled from $2 \mu \mathrm{m}$ to $22 \mu \mathrm{m}$ by adjusting the sprayed volume of the precursor solution and deposition time. The ZIF-7 membrane prepared by this method showed a $\mathrm{H}_{2} / \mathrm{CO}_{2}$ separation factor of 9.6 and a $\mathrm{H}_{2}$ permeance of $4.61 \times 10^{-7} \mathrm{~mol} \cdot \mathrm{Pa}^{-1} \cdot \mathrm{m}^{-2} \cdot \mathrm{s}^{-1}$ at $25^{\circ} \mathrm{C}$, 4-10 times higher than the previously reported ZIF-7 membranes. Both $\mathrm{H}_{2}$ and $\mathrm{CO}_{2}$ permeances decrease as the increase of temperature while the separation factor increased to $18.3^{\circ} \mathrm{C}$ at $150{ }^{\circ} \mathrm{C}$. The high membrane performances, combined with the good reproducibility and scalability, make this direct spraying approach an intriguing method for the fabrication of ZIF membranes. Unfortunately, these studies on ZIF-7 membranes focused on hydrogen separation, and the ethylene/ethane separation properties of ZIF-7 membranes have not been reported.

In contrast to most microporous molecular sieves, Gascon and co-workers found that ethane is selectively adsorbed over ethylene on ZIF-7 through a gate-opening effect (Figure 14a-c) [131]. The rotational freedom of the ligands in ZIF-7 allows molecules larger than $3 \AA$, such as ethylene and ethane, to enter the pores. The interaction between the linkers and adsorbates strongly affects the ligand conformation and hence results in a gate-opening effect, in which the uptake and release of different molecules is controlled by specific threshold pressures, leaving a window of selective adsorption operation [56,57,132-134]. For the case of $C 2$ molecules, ethane molecules can enter the pores of ZIF-7 at lower pressures than ethylene because the methyl groups fits best in the largest opening of the ZIF-7 cage. As a result, ZIF-7 adsorbents showed remarkable ethane selectivity in binary adsorption breakthrough experiments. This interesting gate-opening effect proves to be effective in discriminating molecules of very similar size and suggests the potential of ZIF-7 membranes for ethylene/ethane separation. Since robust synthesis approaches have already been established, it can be expected that the C2 separation properties of ZIF-7 membranes will soon be reported. 
a)

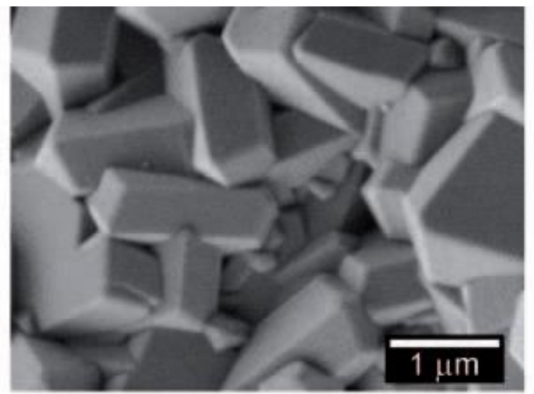

b)

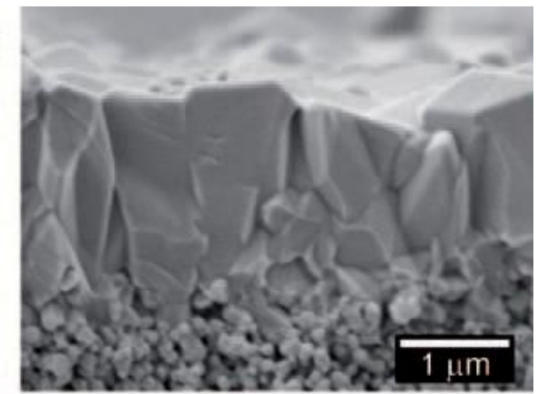

c)

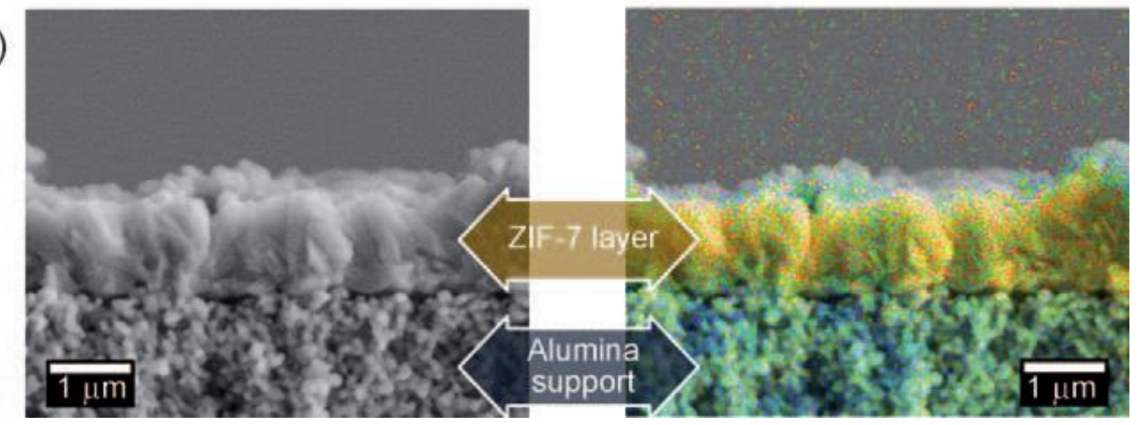

Figure 13. (a) Top view SEM images, (b) cross-section SEM image, and (c) EDXS mapping (orange Zn, cyan Al) of ZIF-7 membrane prepared on alumina support [128].
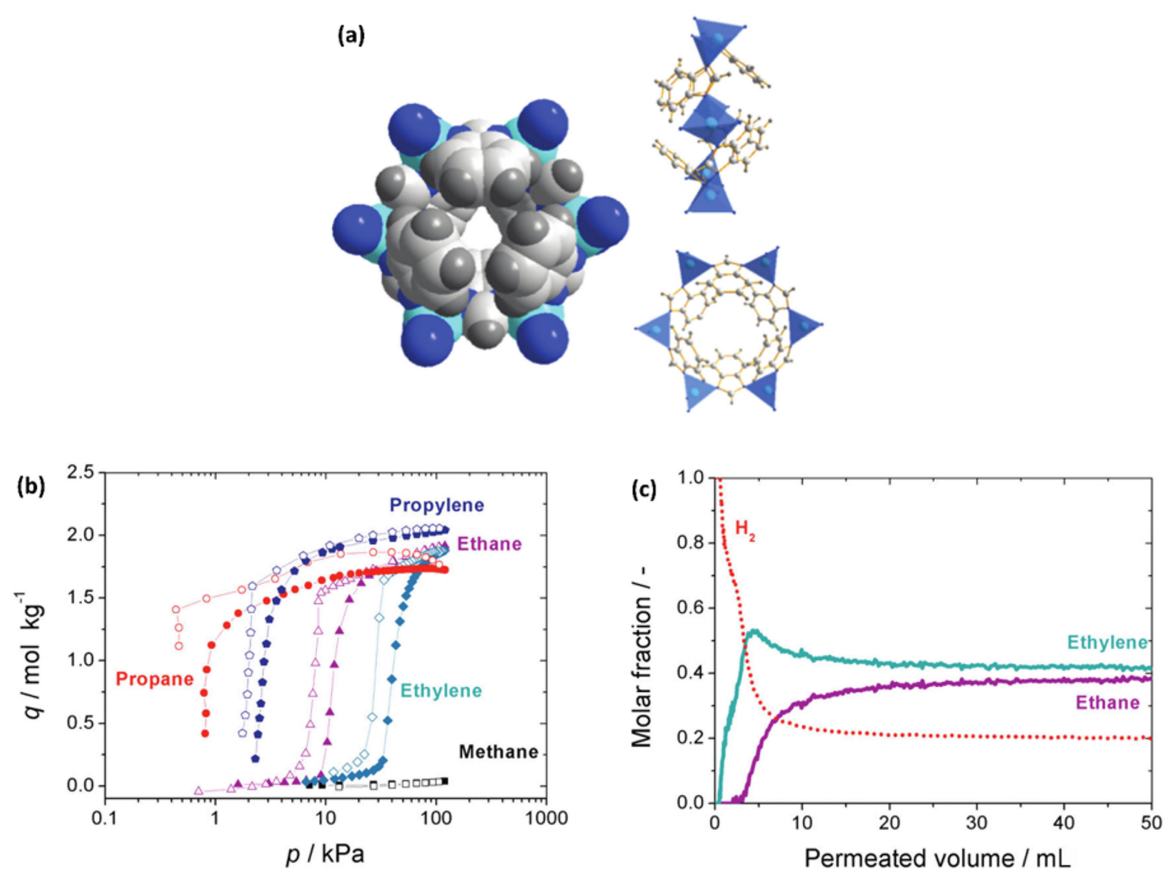

Figure 14. (a) Main cavity of ZIF-7 (Left). Lateral (Top Right) and front (Bottom Right) views of the six-membered-ring pore opening. Zn clusters are represented as polyhedra. (b) Adsorption (closed symbols)-desorption (open symbols) isotherms of several hydrocarbons on ZIF-7 powder at $25{ }^{\circ} \mathrm{C}$. (c) Breakthrough curve obtained for an equimolar mixture of $\mathrm{C}_{2} \mathrm{H}_{4}$ and $\mathrm{C}_{2} \mathrm{H}_{6}$ on a column packed with ZIF-7 pellets at $25{ }^{\circ} \mathrm{C}$ and 1 bar. $\mathrm{H}_{2}$, contributing the $20 \%$ of the mixture flow [131].

\subsection{Mixed-Linker ZIF Membranes}

ZIFs containing multiple linkers, which can be obtained through post-linker exchange or direct incorporation of mixed linkers into the framework during synthesis, possess unique structures and properties that are unavailable from single-linker ZIFs. By using progressively bulkier linkers, 
ZIFs with extra-large pore openings and cages were synthesized by Yaghi's group and used for the removal of octane and p-xylene from humid air [135]. On the other hand, Nair's group demonstrated the continuous tuning of the effective aperture size, hydrophilicity, and organophilicity of ZIFs using mixed-linker ZIFs containing 2-methylimidazole (ZIF-8 linker) and 2-carboxyimidazole (ZIF-90 linker) [136-138]. Variation of the linker composition allows control of the $n$-butane and $i$-butane diffusivities and the $n$-butane/ $i$-butane diffusion selectivity over several orders of magnitude. The mixed-linker ZIFs with tunable adsorption and diffusion properties provide a new platform for molecular separations. More recently, Jeong's group successfully adapted this approach for the synthesis of mixed-linker hybrid ZIF membranes consisting of 2-methylimidazolate (ZIF-8 linker) and benzimidazolate (ZIF-7 linker) linkers, termed ZIF-7-8 membranes (Figure 15a-c) [139]. Both $\mathrm{H}_{2} / \mathrm{CH}_{4}$ and $\mathrm{CO}_{2} / \mathrm{CH}_{4}$ separation factors increase gradually as more bIM is incorporated into the framework, suggesting the reduction of the effective membrane pore size caused by the increasing incorporation of bulky benzimidazolate linker. Considering its pore size range, ZIF-7-8 membrane is potentially a good candidate for ethylene/ethane separation.
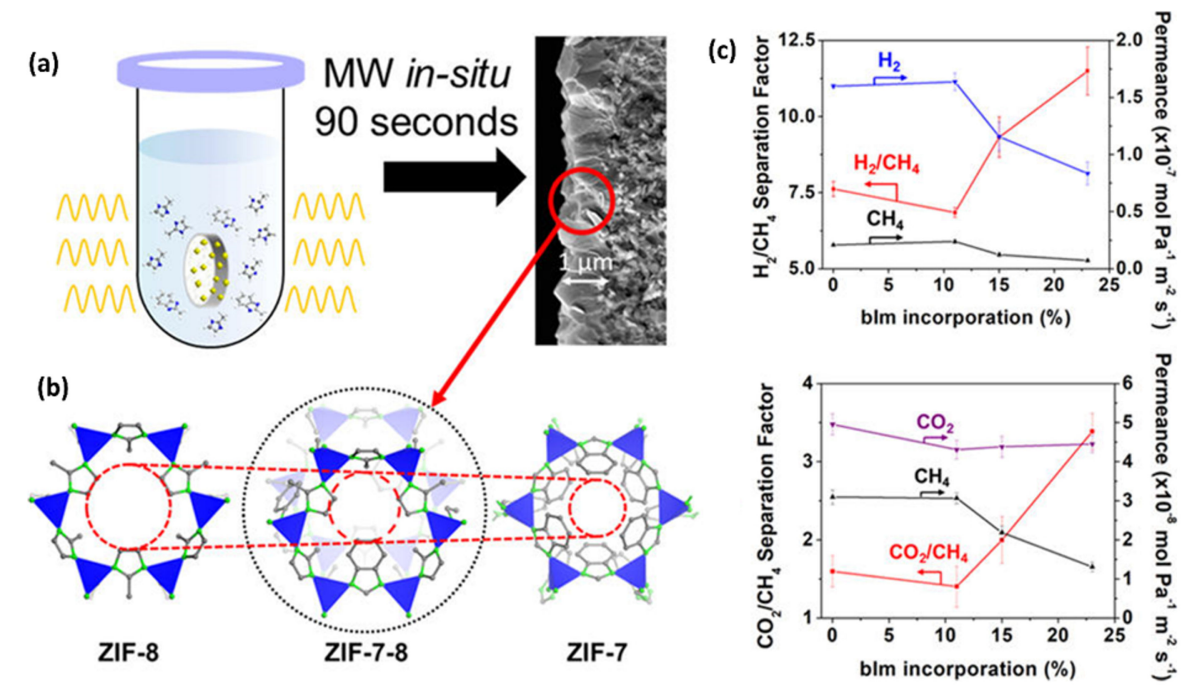

Figure 15. (a) Schematic illustration for the microwave-assisted in situ synthesis of mixed linker ZIF-7-8 membranes. (b) comparison of effective pore aperture of ZIF-8, ZIF-7, and mixed linker ZIF-7-8. (c) Effect of bIm incorporation on $\mathrm{H}_{2} / \mathrm{CH}_{4}$ and $\mathrm{CO}_{2} / \mathrm{CH}_{4}$ separation performances of ZIF-7-8 membranes [139].

\section{Conclusions and Outlook}

ZIF molecular sieve membranes represent a promising separation technique for olefin/paraffin separation. The propylene/propane separation performances of ZIF-8, ZIF-67, and mixed linker ZIF membranes have well surpassed the upper bound of polymer and other microporous inorganic membranes. High quality ZIF membranes can be fabricated on porous ceramic and polymeric supports of flat sheet, tubular, or hollow fiber geometries through a variety of conventional and emerging methods. In situ synthesis and seeded growth, originally developed for the synthesis of zeolite membranes, have been successfully adapted to grow continuous ZIF membranes. Counter-diffusion synthesis is capable of producing membranes with enhanced microstructure and separation property and healing the defects in a defective membrane. Interfacial microfluidic processing allows for the controllable formation and location of ZIF membranes on polymer hollow fibers and offers the potential to realize scalable molecular sieving membranes. Vapor-phase processing based on atomic layer deposition technology has established a reliable, scalable, solvent-free approach for the fabrication of ZIF and possibly other MOF membranes. ZIF membranes prepared by fast current driven synthesis possess suppressed linker mobility and drastically enhanced selectivity. In addition, ZIF membranes 
have demonstrated good stability for the continuous separation of propylene/propane mixture under dry conditions.

ZIF-8 membranes have been extensively studied and their excellent propylene/propane separation properties have been well documented. Despite the promising energy savings, there are thus far no industrial gas separations using ZIF-8 membranes. Future efforts are needed to overcome the barriers for practical applications, such as improving the reliability and scalability of membrane processing, reducing membrane cost and evaluating the membrane performance and long-term stability using real industrial gas streams. On the other hand, further enhancement of the propylene/propane separation performance appears to be limited by the framework flexibility of ZIF-8. Very recently, ZIF membranes containing unconventional ZIF-8 structures prepared by the ligand-induced permselectivation and fast current driven synthesis approaches exhibited much enhanced molecular sieving capability than other ZIF-8 membranes. The full potential of these two methods needs to be further explored. Compared to ZIF-8, ZIF-67 possesses a much higher intrinsic propylene/propane selectivity attributed to the more rigid framework. Owing to the structural similarities, it is expected that many processing methods developed for ZIF- 8 membranes are applicable to ZIF-67 membranes. This could lead to the creation of a new membrane system with enhanced separation properties.

In contrast to the unique propylene/propane separation property, all ZIF membranes reported have failed to outperform polymer and CMS membranes for the separation of ethylene and ethane. New ZIF crystal structures should be explored to identify the desired pore structure and pore size regime for ethylene/ethane separation. The recent progress on the successful design and synthesis of mixed-linker ZIF membranes with tunable pore size has added another dimension to tune the molecular sieving properties of ZIF membranes. It is worth noting that membrane selectivity is determined by the product of diffusion selectivity and sorption selectivity. Considering the difficulties of achieving high ethylene/ethane diffusion selectivity, increasing the preferential adsorption of ethylene by tailoring the chemistry properties of ZIF membranes could be a more effective approach to enhance the ethylene/ethane membrane selectivity. Because of the huge number of ZIFs available and the high tunability of their pore size and chemistry properties, it can be expected that new ZIF membranes with superb ethylene/ethane separation properties will be synthesized.

Author Contributions: Writing_original draft preparation, review and editing, X.M. and D.L.

Funding: This work was supported by the start-up funds from University of Wisconsin-Milwaukee.

Acknowledgments: D.L. acknowledges the funding support from Foshan University.

Conflicts of Interest: The authors declare no conflicts of interest.

\section{References}

1. Sholl, D.S.; Lively, R.P. Seven Chemical Separations to Change the World. Nature 2016, 532, 435-436. [CrossRef] [PubMed]

2. Galizia, M.; Chi, W.S.; Smith, Z.P.; Merkel, T.C.; Baker, R.W.; Freeman, B.D. 50th Anniversary Perspective: Polymers and Mixed Matrix Membranes for Gas and Vapor Separation: A Review and Prospective Opportunities. Macromolecules 2017, 50, 7809-7843. [CrossRef]

3. Ryan, L.; Burns, W.J.K. Defining the Challenges for $\mathrm{C}_{3} \mathrm{H}_{6} / \mathrm{C}_{3} \mathrm{H}_{8}$ Separation Using Polymeric Membranes. J. Memb. Sci. 2003, 211, 299-309.

4. Rungta, M.; Zhang, C.; Koros, W.J.; Xu, L. Membrane-Based Ethylene/Ethane Separation: The Upper Bound and Beyond. AIChE J. 2013, 59, 3475-3489. [CrossRef]

5. Ma, X.; Lin, B.K.; Wei, X.; Kniep, J.; Lin, Y.S. Gamma-Alumina Supported Carbon Molecular Sieve Membrane for Propylene/Propane Separation. Ind. Eng. Chem. Res. 2013, 52, 4297-4305. [CrossRef]

6. Eldridge, R.B. Olefin/Paraffin Separation Technology: A Review. Ind. Eng. Chem. Res. 1993, 32, 2208-2212. [CrossRef] 
7. Safarik, D.J.; Eldridge, R.B. Olefin/Paraffin Separations by Reactive Absorption: A Review. Ind. Eng. Chem. Res. 1998, 37, 2571-2581. [CrossRef]

8. Alshehri, A.K.; Lai, Z. Attainability and Minimum Energy of Multiple-Stage Cascade Membrane Systems. J. Memb. Sci. 2015, 495, 284-293. [CrossRef]

9. Lee, U.; Kim, J.; Seok Chae, I.; Han, C. Techno-Economic Feasibility Study of Membrane Based Propane/Propylene Separation Process. Chem. Eng. Process. Process Intensif. 2017, 119, 62-72. [CrossRef]

10. Baker, R.W. Future Directions of Membrane Gas Separation Technology. Ind. Eng. Chem. Res. 2002, 41, $1393-1411$. [CrossRef]

11. Sanders, D.F.; Smith, Z.P.; Guo, R.; Robeson, L.M.; McGrath, J.E.; Paul, D.R.; Freeman, B.D. Energy-Efficient Polymeric Gas Separation Membranes for a Sustainable Future: A Review. Polymer 2013, 54, 4729-4761. [CrossRef]

12. Faiz, R.; Li, K. Polymeric Membranes for Light Olefin/Paraffin Separation. Desalination 2012, $287,82-97$. [CrossRef]

13. Campos, A.C.C.; Dos Reis, R.A.; Ortiz, A.; Gorri, D.; Ortiz, I. A Perspective of Solutions for Membrane Instabilities in Olefin/Paraffin Separations: A Review. Ind. Eng. Chem. Res. 2018, 57, 10071-10085. [CrossRef]

14. Koros, W.J.; Zhang, C. Materials for Next-Generation Molecularly Selective Synthetic Membranes. Nat. Mater. 2017, 16, 289-297. [CrossRef]

15. Ma, X.L.; Lin, J.Y.S. Preparation Chemistry of Inorganic Membranes. Mod. Inorg. Synth. Chem. Second Ed. 2017, 669-686.

16. Lin, Y.S.; Kumakiri, I.; Nair, B.N.; Alsyouri, H. Microporous Inorganic Membranes. Sep. Purif. Methods 2002, 31. [CrossRef]

17. Lin, Y.; Duke, M.C. Recent Progress in Polycrystalline Zeolite Membrane Research. Curr. Opin. Chem. Eng. 2013, 2, 209-216. [CrossRef]

18. Rangnekar, N.; Mittal, N.; Elyassi, B.; Caro, J.; Tsapatsis, M. Zeolite Membranes-A Review and Comparison with MOFs. Chem. Soc. Rev. 2015, 44, 7128-7154. [CrossRef] [PubMed]

19. Gascon, J.; Kapteijn, F.; Zornoza, B.; Sebastián, V.; Casado, C.; Coronas, J. Practical Approach to Zeolitic Membranes and Coatings: State of the Art, Opportunities, Barriers, and Future Perspectives. Chem. Mater. 2012, 24, 2829-2844. [CrossRef]

20. Gascon, J.; Kapteijn, F. Metal-Organic Framework Membranes-High Potential, Bright Future? Angew. Chemie Int. Ed. 2010, 49, 1530-1532. [CrossRef]

21. Caro, J. Are MOF Membranes Better in Gas Separation than Those Made of Zeolites? Curr. Opin. Chem. Eng. 2011, 1, 77-83. [CrossRef]

22. Duan, J.; Pan, Y.; Liu, G.; Jin, W. Metal-Organic Framework Adsorbents and Membranes for Separation Applications. Curr. Opin. Chem. Eng. 2018, 20, 122-131. [CrossRef]

23. Liu, G.; Chernikova, V.; Liu, Y.; Zhang, K.; Belmabkhout, Y.; Shekhah, O.; Zhang, C.; Yi, S.; Eddaoudi, M.; Koros, W.J. Mixed Matrix Formulations with MOF Molecular Sieving for Key Energy-Intensive Separations. Nat. Mater. 2018, 17, 283-289. [CrossRef] [PubMed]

24. Yaghi, O.M.; O'Keeffe, M.; Ockwig, N.W.; Chae, H.K.; Eddaoudi, M.; Kim, J. Reticular Synthesis and the Design of New Materials. Nature 2003, 423, 705-714. [CrossRef] [PubMed]

25. Li, H.; Eddaoudi, M.; O'Keeffe, M.; Yaghi, O.M. Design and Synthesis of an Exceptionally Stable and Highly Porous Metal-Organic Framework. Nature 1999, 402, 276-279. [CrossRef]

26. Li, J.-R.; Sculley, J.; Zhou, H. Metal-Organic Frameworks for Separations. Chem. Rev. 2012, 112, 869-932. [CrossRef] [PubMed]

27. Furukawa, H.; Cordova, K.E.; O'Keeffe, M.; Yaghi, O.M. The Chemistry and Applications of Metal-Organic Frameworks. Science 2013, 341, 1230444. [CrossRef] [PubMed]

28. Banerjee, R.; Phan, A.; Wang, B.; Knobler, C.; Furukawa, H.; O’keeffe, M.; Yaghi, O.M. High-Throughput Synthesis of Zeolitic Imidazolate Frameworks and Application to $\mathrm{CO}_{2}$ Capture. Science 2008, 319, 939-943. [CrossRef] [PubMed]

29. Sumida, K.; Rogow, D.L.; Mason, J.A.; McDonald, T.M.; Bloch, E.D.; Herm, Z.R.; Bae, T.H.; Long, J.R. Carbon Dioxide Capture by Metal Organic Frameworks. Chem. Rev. 2012, 112, 724-781. [CrossRef] [PubMed]

30. Liu, Y.; Ban, Y.; Yang, W. Microstructural Engineering and Architectural Design of Metal-Organic Framework Membranes. Adv. Mater. 2017, 29, 1-17. [CrossRef] 
31. Liu, Y.; Hu, J.; Ma, X.; Liu, J.; Lin, Y.S. Mechanism of $\mathrm{CO}_{2}$ adsorption on $\mathrm{Mg} / \mathrm{DOBDC}$ with Elevated $\mathrm{CO}_{2}$ loading. Fuel 2016, 181, 340-346. [CrossRef]

32. Shete, M.; Kumar, P.; Bachman, J.E.; Ma, X.; Smith, Z.P.; Xu, W.; Mkhoyan, K.A.; Long, J.R.; Tsapatsis, M. On the Direct Synthesis of $\mathrm{Cu}(\mathrm{BDC}) \mathrm{MOF}$ Nanosheets and Their Performance in Mixed Matrix Membranes. J. Memb. Sci. 2018, 549, 312-320. [CrossRef]

33. Zhao, Z.; Ma, X.; Li, Z.; Lin, Y.S. Synthesis, Characterization and Gas Transport Properties of MOF-5 Membranes. J. Memb. Sci. 2011, 382, 82-90. [CrossRef]

34. Kang, Z.; Ding, J.; Fan, L.; Xue, M.; Zhang, D.; Gao, L.; Qiu, S. Preparation of a MOF Membrane with 3-Aminopropyltriethoxysilane as Covalent Linker for Xylene Isomers Separation. Inorg. Chem. Commun. 2013, 30, 74-78. [CrossRef]

35. Liu, Y.; Liu, G.; Zhang, C.; Qiu, W.; Yi, S.; Chernikova, V.; Chen, Z.; Belmabkhout, Y.; Shekhah, O.; Eddaoudi, M.; et al. Enhanced $\mathrm{CO}_{2} / \mathrm{CH}_{4}$ Separation Performance of a Mixed Matrix Membrane Based on Tailored MOF-Polymer Formulations. Adv. Sci. 2018, 5, 2-6. [CrossRef] [PubMed]

36. Liu, X.; Demir, N.K.; Wu, Z.; Li, K. Highly Water-Stable Zirconium Metal-Organic Framework UiO-66 Membranes Supported on Alumina Hollow Fibers for Desalination. J. Am. Chem. Soc. 2015, 137, 6999-7002. [CrossRef] [PubMed]

37. Wang, C.; Liu, X.; Keser Demir, N.; Chen, J.P.; Li, K. Applications of Water Stable Metal-Organic Frameworks. Chem. Soc. Rev. 2016, 45, 5107-5134. [CrossRef]

38. Zhang, X.; Zhao, Y.; Mu, S.; Jiang, C.; Song, M.; Fang, Q.; Xue, M.; Qiu, S.; Chen, B. UiO-66-Coated Mesh Membrane with Underwater Superoleophobicity for High-Efficiency Oil-Water Separation. ACS Appl. Mater. Interfaces 2018, 10, 17301-17308. [CrossRef]

39. Cao, J.; Su, Y.; Liu, Y.; Guan, J.; He, M.; Zhang, R.; Jiang, Z. Self-Assembled MOF Membranes with Underwater Superoleophobicity for Oil/Water Separation. J. Memb. Sci. 2018, 566, 268-277. [CrossRef]

40. Campbell, J.; Székely, G.; Davies, R.P.; Braddock, D.C.; Livingston, A.G. Fabrication of hybrid polymer/metal organic framework membranes: Mixed matrix membranes versus in situ growth. J. Mater. Chem. A 2014, 2, 9260-9271. [CrossRef]

41. Campbell, J.; Burgal, J.D.S.; Szekely, G.; Davies, R.P.; Braddock, D.C.; Livingston, A. Hybrid Polymer/MOF Membranes for Organic Solvent Nanofiltration (OSN): Chemical Modification and the Quest for Perfection. J. Memb. Sci. 2016, 503, 166-176. [CrossRef]

42. Dong, X.; Lin, Y.S. Synthesis of an Organophilic ZIF-71 Membrane for Pervaporation Solvent Separation. Chem. Commun. 2013, 49, 1196-1198. [CrossRef] [PubMed]

43. Ibrahim, A.; Lin, Y.S. Pervaporation Separation of Organic Mixtures by MOF-5 Membranes. Ind. Eng. Chem. Res. 2016, 55, 8652-8658. [CrossRef]

44. Jeong, G.Y.; Singh, A.K.; Kim, M.G.; Gyak, K.W.; Ryu, U.; Choi, K.M.; Kim, D.P. Metal-Organic Framework Patterns and Membranes with Heterogeneous Pores for Flow-Assisted Switchable Separations. Nat. Commun. 2018, 9, 3968. [CrossRef]

45. Lin, Y.S. Inorganic Membranes for Process Intensification: Challenges and Perspective. Ind. Eng. Chem. Res. 2018. article ASAP. [CrossRef]

46. Lee, S.; Kim, J.; Kim, J.; Lee, D. Zeolitic Imidazolate Framework Membrane with Marked Thermochemical Stability for High-Temperature Catalytic Processes. Chem. Mater. 2018, 30, 447-455. [CrossRef]

47. Park, K.S.; Ni, Z.; Cote, A.P.; Choi, J.Y.; Huang, R.; Uribe-Romo, F.J.; Chae, H.K.; O’Keeffe, M.; Yaghi, O.M. Exceptional Chemical and Thermal Stability of Zeolitic Imidazolate Frameworks. Proc. Natl. Acad. Sci. USA 2006, 103, 10186-10191. [CrossRef] [PubMed]

48. Lai, Z. Development of ZIF-8 Membranes: Opportunities and Challenges for Commercial Applications. Curr. Opin. Chem. Eng. 2018, 20, 78-85. [CrossRef]

49. Liu, Y.; Kasik, A.; Linneen, N.; Liu, J.; Lin, Y.S. Adsorption and Diffusion of Carbon Dioxide on ZIF-68. Chem. Eng. Sci. 2014, 118, 32-40. [CrossRef]

50. Dong, X.; Huang, K.; Liu, S.; Ren, R.; Jin, W.; Lin, Y.S. Synthesis of Zeolitic Imidazolate Framework-78 Molecular-Sieve Membrane: Defect Formation and Elimination. J. Mater. Chem. 2012, 22, 19222-19227. [CrossRef]

51. Li, K.; Olson, D.H.; Seidel, J.; Emge, T.J.; Gong, H.; Zeng, H.; Li, J. Zeolitic Imidazolate Frameworks for Kinetic Separation of Propane and Propene. J. Am. Chem. Soc. 2009, 131, 10368-10369. [CrossRef] [PubMed]

52. Zhang, C.; Lively, R.P.; Zhang, K.; Johnson, J.R.; Karvan, O.; Koros, W.J. Unexpected Molecular Sieving Properties of Zeolitic Imidazolate Framework-8. J. Phys. Chem. Lett. 2012, 3, 2130-2134. [CrossRef] [PubMed] 
53. Shekhah, O.; Liu, J.; Fischer, R.A.; Wöll, C. MOF Thin Films: Existing and Future Applications. Chem. Soc. Rev. 2011, 40, 1081-1106. [CrossRef] [PubMed]

54. Qiu, S.; Xue, M.; Zhu, G. Metal-Organic Framework Membranes: From Synthesis to Separation Application. Chem. Soc. Rev. 2014, 43, 6116-6140. [CrossRef] [PubMed]

55. Lin, Y.S. Metal Organic Framework Membranes for Separation Applications. Curr. Opin. Chem. Eng. 2015, 8, 21-28. [CrossRef]

56. Krokidas, P.; Castier, M.; Moncho, S.; Brothers, E.; Economou, I.G. Molecular Simulation Studies of the Diffusion of Methane, Ethane, Propane, and Propylene in ZIF-8. J. Phys. Chem. C 2015, 119, 27028-27037. [CrossRef]

57. Fairen-Jimenez, D.; Moggach, S.A.; Wharmby, M.T.; Wright, P.A.; Parsons, S.; Düren, T. Opening the Gate: Framework Flexibility in ZIF-8 Explored by Experiments and Simulations. J. Am. Chem. Soc. 2011, 133, 8900-8902. [CrossRef]

58. Kaewruksa, B.; Vchirawongkwin, V.; Ruangpornvisuti, V. Adsorption of Propane and Propylene in Zeolitic Imidazolate Framework ZIF-8 Pore: Periodic SCC-DFTB Method. Adsorption 2018, 24, 691-701. [CrossRef]

59. Böhme, U.; Barth, B.; Paula, C.; Kuhnt, A.; Schwieger, W.; Mundstock, A.; Caro, J.; Hartmann, M. Ethene/Ethane and Propene/Propane Separation via the Olefin and Paraffin Selective Metal-Organic Framework Adsorbents CPO-27 and ZIF-8. Langmuir 2013, 29, 8592-8600. [CrossRef]

60. Bux, H.; Liang, F.; Li, Y.; Cravillon, J.; Wiebcke, M.; Caro, J. Zeolitic Imidazolate Framework Molecular Sieving Membrane Titania Support. J. Am. Chem. Soc. 2009, 131, 16000-16001. [CrossRef]

61. Pan, Y.; Li, T.; Lestari, G.; Lai, Z. Effective Separation of Propylene/Propane Binary Mixtures by ZIF-8 Membranes. J. Memb. Sci. 2012, 390-391, 93-98. [CrossRef]

62. Shah, M.; Kwon, H.T.; Tran, V.; Sachdeva, S.; Jeong, H.K. One Step in Situ Synthesis of Supported Zeolitic Imidazolate Framework ZIF-8 Membranes: Role of Sodium Formate. Microporous Mesoporous Mater. 2013, 165, 63-69. [CrossRef]

63. Wang, J.W.; Li, N.X.; Li, Z.R.; Wang, J.R.; Xu, X.; Chen, C.S. Preparation and Gas Separation Properties of Zeolitic Imidazolate Frameworks-8 (ZIF-8) Membranes Supported on Silicon Nitride Ceramic Hollow Fibers. Ceram. Int. 2016, 42, 8949-8954. [CrossRef]

64. Huang, A.; Bux, H.; Steinbach, F.; Caro, J. Molecular-Sieve Membrane with Hydrogen Permselectivity: ZIF-22 in LTA Topology Prepared with 3-Aminopropyltriethoxysilane as Covalent Linker. Angew. Chemie Int. Ed. 2010, 49, 4958-4961. [CrossRef] [PubMed]

65. Huang, A.; Dou, W.; Caro, J. Steam-Stable Zeolitic Imidazolate Framework ZIF-90 Membrane with Hydrogen Selectivity through Covalent Functionalization. J. Am. Chem. Soc. 2010, 132, 15562-15564. [CrossRef] [PubMed]

66. Tanaka, S.; Okubo, K.; Kida, K.; Sugita, M.; Takewaki, T. Grain Size Control of ZIF-8 Membranes by Seeding-Free Aqueous Synthesis and Their Performances in Propylene/Propane Separation. J. Memb. Sci. 2017, 544, 306-311. [CrossRef]

67. Liu, Q.; Wang, N.; Caro, J.; Huang, A. Bio-Inspired Polydopamine: A Versatile and Powerful Platform for Covalent Synthesis of Molecular Sieve Membranes. J. Am. Chem. Soc. 2013, 135, 17679-17682. [CrossRef] [PubMed]

68. Yu, J.; Pan, Y.; Wang, C.; Lai, Z. ZIF-8 Membranes with Improved Reproducibility Fabricated from Sputter-Coated ZnO/Alumina Supports. Chem. Eng. Sci. 2016, 141, 119-124. [CrossRef]

69. Kong, L.; Zhang, X.; Liu, H.; Qiu, J. Synthesis of a Highly Stable ZIF-8 Membrane on a Macroporous Ceramic Tube by Manual-Rubbing ZnO Deposition as a Multifunctional Layer. J. Memb. Sci. 2015, 490, 354-363. [CrossRef]

70. Xie, Z.; Yang, J.; Wang, J.; Bai, J.; Yin, H.; Yuan, B.; Lu, J.; Zhang, Y.; Zhou, L.; Duan, C. Deposition of Chemically Modified $\alpha$-A12O3particles for High Performance ZIF-8 Membrane on a Macroporous Tube. Chem. Commun. 2012, 48, 5977-5979. [CrossRef]

71. Zhu, Y.; Liu, Q.; Caro, J.; Huang, A. Highly Hydrogen-Permselective Zeolitic Imidazolate Framework ZIF-8 Membranes Prepared on Coarse and Macroporous Tubes through Repeated Synthesis. Sep. Purif. Technol. 2015, 146, 68-74. [CrossRef]

72. Cravillon, J.; Nayuk, R.; Springer, S.; Feldhoff, A.; Huber, K.; Wiebcke, M. Controlling Zeolitic Imidazolate Framework Nano- and Microcrystal Formation: Insight into Crystal Growth by Time-Resolved in Situ Static Light Scattering. Chem. Mater. 2011, 23, 2130-2141. [CrossRef] 
73. Zhang, K.; Lively, R.P.; Zhang, C.; Koros, W.J.; Chance, R.R. Investigating the Intrinsic Ethanol/Water Separation Capability of ZIF-8: An Adsorption and Diffusion Study. J. Phys. Chem. C 2013, 117, 7214-7225. [CrossRef]

74. Zhang, K.; Lively, R.P.; Dose, M.E.; Brown, A.J.; Zhang, C.; Chung, J.; Nair, S.; Koros, W.J.; Chance, R.R. Alcohol and Water Adsorption in Zeolitic Imidazolate Frameworks. Chem. Commun. 2013, 49, 3245-3247. [CrossRef] [PubMed]

75. Pan, Y.; Liu, Y.; Zeng, G.; Zhao, L.; Lai, Z. Rapid Synthesis of Zeolitic Imidazolate Framework-8 (ZIF-8) Nanocrystals in an Aqueous System. Chem. Commun. 2011, 47, 2071-2073.

76. Pan, Y.; Heryadi, D.; Zhou, F.; Zhao, L.; Lestari, G.; Su, H.; Lai, Z. Tuning the Crystal Morphology and Size of Zeolitic Imidazolate Framework-8 in Aqueous Solution by Surfactants. CrystEngComm 2011, 13, 6937-6940.

77. Pan, Y.; Lai, Z. Sharp Separation of C2/C3 Hydrocarbon Mixtures by Zeolitic Imidazolate Framework-8 (ZIF-8) Membranes Synthesized in Aqueous Solutions. Chem. Commun. 2011, 47, 10275-10277. [CrossRef]

78. Liu, D.; Ma, X.; Xi, H.; Lin, Y.S. Gas Transport Properties and Propylene/Propane Separation Characteristics of ZIF-8 Membranes. J. Memb. Sci. 2014, 451, 85-93. [CrossRef]

79. Pan, Y.; Liu, W.; Zhao, Y.; Wang, C.; Lai, Z. Improved ZIF-8 Membrane: Effect of Activation Procedure and Determination of Diffusivities of Light Hydrocarbons. J. Memb. Sci. 2015, 493, 88-96. [CrossRef]

80. Kwon, H.T.; Jeong, H.K. Highly Propylene-Selective Supported Zeolite-Imidazolate Framework (ZIF-8) Membranes Synthesized by Rapid Microwave-Assisted Seeding and Secondary Growth. Chem. Commun. 2013, 49, 3854-3856. [CrossRef]

81. Yin, H.; Lee, T.; Choi, J.; Yip, A.C.K. On the Zeolitic Imidazolate Framework-8 (ZIF-8) Membrane for Hydrogen Separation from Simulated Biomass-Derived Syngas. Microporous Mesoporous Mater. 2016, 233, 70-77. [CrossRef]

82. Sun, J.; Yu, C.; Jeong, H.-K. Propylene-Selective Thin Zeolitic Imidazolate Microwave Seeding and Solvothermal. Crystals 2018, 8, 373. [CrossRef]

83. Tao, K.; Kong, C.; Chen, L. High Performance ZIF-8 Molecular Sieve Membrane on Hollow Ceramic Fiber via Crystallizing-Rubbing Seed Deposition. Chem. Eng. J. 2013, 220, 1-5. [CrossRef]

84. Pan, Y.; Wang, B.; Lai, Z. Synthesis of Ceramic Hollow Fiber Supported Zeolitic Imidazolate Framework-8 (ZIF-8) Membranes with High Hydrogen Permeability. J. Memb. Sci. 2012, 421-422, 292-298. [CrossRef]

85. Huang, K.; Dong, Z.; Li, Q.; Jin, W. Growth of a ZIF-8 Membrane on the Inner-Surface of a Ceramic Hollow Fiber via Cycling Precursors. Chem. Commun. 2013, 49, 10326-10328. [CrossRef] [PubMed]

86. Yao, J.; Dong, D.; Li, D.; He, L.; Xu, G.; Wang, H. Contra-Diffusion Synthesis of ZIF-8 Films on a Polymer Substrate. Chem. Commun. 2011, 47, 2559-2561. [CrossRef] [PubMed]

87. Kwon, H.T.; Jeong, H. In Situ Synthesis of Thin Zeolitic-Imidazolate Framework ZIF-8 Membranes Exhibiting Exceptionally High Propylene/Propane Separation. J. Am. Chem. Soc. 2013, 135, 10763-10768. [CrossRef] [PubMed]

88. Taek, H.; Jeong, H. Improving Propylene/Propane Separation Performance of Zeolitic-Imidazolate Framework ZIF-8 Membranes. Chem. Eng. Sci. 2015, 124, 20-26.

89. Jang, E.; Kim, E.; Kim, H.; Lee, T.; Yeom, H.J.; Kim, Y.W.; Choi, J. Formation of ZIF-8 Membranes inside Porous Supports for Improving Both Their $\mathrm{H}_{2} / \mathrm{CO}_{2}$ separation Performance and Thermal/Mechanical Stability. J. Memb. Sci. 2017, 540, 430-439. [CrossRef]

90. Hara, N.; Yoshimune, M.; Negishi, H.; Haraya, K.; Hara, S.; Yamaguchi, T. Microporous and Mesoporous Materials ZIF-8 Membranes Prepared at Miscible and Immiscible Liquid-Liquid Interfaces. Microporous Mesoporous Mater. 2015, 206, 75-80. [CrossRef]

91. Hara, N.; Yoshimune, M.; Negishi, H.; Haraya, K.; Hara, S.; Yamaguchi, T. Thickness Reduction of the Zeolitic Imidazolate Framework-8 Membrane by Controlling the Reaction Rate during the Membrane Preparation. J. Chem. Eng. Jpn. 2014, 47, 770-776. [CrossRef]

92. Hara, N.; Yoshimune, M.; Negishi, H.; Haraya, K.; Hara, S.; Yamaguchi, T. Effect of Temperature on Synthesis of ZIF-8 Membranes for Propylene/Propane Separation by Counter Diffusion Method. J. Jpn. Petrol. Inst. 2015, 58, 237-244.

93. Brown, A.J.; Brunelli, N.A.; Eum, K.; Rashidi, F.; Johnson, J.R.; Koros, W.J.; Jones, C.W.; Nair, S.; Gascon, J.; Kapteijn, F; et al. Interfacial Microfluidic Processing of Metal-Organic Framework Hollow Fiber Membranes. Science 2014, 345, 72-75. [PubMed] 
94. Eum, K.; Ma, C.; Rownaghi, A.; Jones, C.W.; Nair, S. ZIF-8 Membranes via Interfacial Microfluidic Processing in Polymeric Hollow Fibers: Efficient Propylene Separation at Elevated Pressures. ACS Appl. Mater. Interfaces 2016, 8, 25337-25342. [CrossRef] [PubMed]

95. Eum, K.; Rownaghi, A.; Choi, D.; Bhave, R.R.; Jones, C.W.; Nair, S. Fluidic Processing of High-Performance ZIF-8 Membranes on Polymeric Hollow Fibers: Mechanistic Insights and Microstructure Control. Adv. Funct. Mater. 2016, 26, 5011-5018.

96. Eum, K.; Ma, C.; Koh, D.Y.; Rashidi, F.; Li, Z.; Jones, C.W.; Lively, R.P.; Nair, S. Zeolitic Imidazolate Framework Membranes Supported on Macroporous Carbon Hollow Fibers by Fluidic Processing Techniques. Adv. Mater. Interfaces 2017, 4, 1-6. [CrossRef]

97. Cacho-Bailo, F.; Catalán-Aguirre, S.; Etxeberría-Benavides, M.; Karvan, O.; Sebastian, V.; Téllez, C.; Coronas, J. Metal-Organic Framework Membranes on the Inner-Side of a Polymeric Hollow Fiber by Microfluidic Synthesis. J. Memb. Sci. 2015, 476, 277-285. [CrossRef]

98. Marti, A.M.; Wickramanayake, W.; Dahe, G.; Sekizkardes, A.; Bank, T.L.; Hopkinson, D.P.; Venna, S.R. Continuous Flow Processing of ZIF-8 Membranes on Polymeric Porous Hollow Fiber Supports for $\mathrm{CO}_{2}$ Capture. ACS Appl. Mater. Interfaces 2017, 9, 5678-5682. [PubMed]

99. Lee, M.J.; Abdul Hamid, M.R.; Lee, J.; Kim, J.S.; Lee, Y.M.; Jeong, H.K. Ultrathin Zeolitic-Imidazolate Framework ZIF-8 Membranes on Polymeric Hollow Fibers for Propylene/Propane Separation. J. Memb. Sci. 2018, 559, 28-34. [CrossRef]

100. Pham, T.C.T.; Nguyen, T.H.; Yoon, K.B. Gel-Free Secondary Growth of Uniformly Oriented Silica MFI Zeolite Films and Application for Xylene Separation. Angew. Chemie Int. Ed. 2013, 52, 8693-8698. [CrossRef]

101. Kwon, H.T.; Jeong, H.K.; Lee, A.S.; An, H.S.; Lee, T.; Jang, E.; Lee, J.S.; Choi, J. Defect-Induced Ripening of Zeolitic-Imidazolate Framework ZIF-8 and Its Implication to Vapor-Phase Membrane Synthesis. Chem. Commun. 2016, 52, 11669-11672. [CrossRef] [PubMed]

102. Ma, X.; Kumar, P.; Mittal, N.; Khlyustova, A.; Daoutidis, P.; Andre Mkhoyan, K.; Tsapatsis, M. Zeolitic Imidazolate Framework Membranes Made by Ligand-Induced Permselectivation. Science 2018, 361, $1008-1011$. [CrossRef] [PubMed]

103. Jeon, M.Y.; Kim, D.; Kumar, P.; Lee, P.S.; Rangnekar, N.; Bai, P.; Shete, M.; Elyassi, B.; Lee, H.S.; Narasimharao, K.; et al. Ultra-Selective High-Flux Membranes from Directly Synthesized Zeolite Nanosheets. Nature 2017, 543, 690-694. [CrossRef] [PubMed]

104. Agrawal, K.V.; Topuz, B.; Pham, T.C.T.; Nguyen, T.H.; Sauer, N.; Rangnekar, N.; Zhang, H.; Narasimharao, K.; Basahel, S.N.; Francis, L.F.; et al. Oriented MFI Membranes by Gel-Less Secondary Growth of Sub-100 Nm MFI-Nanosheet Seed Layers. Adv. Mater. 2015, 27, 3243-3249. [CrossRef]

105. Stassen, I.; Styles, M.; Grenci, G.; Van Gorp, H.; Vanderlinden, W.; De Feyter, S.; Falcaro, P.; De Vos, D.; Vereecken, P.; Ameloot, R. Chemical Vapour Deposition of Zeolitic Imidazolate Framework Thin Films. Nat. Mater. 2016, 15, 304-310. [CrossRef]

106. Li, W.; Su, P.; Li, Z.; Xu, Z.; Wang, F.; Ou, H.; Zhang, J.; Zhang, G.; Zeng, E. Ultrathin Metal-Organic Framework Membrane Production by Gel-Vapour Deposition. Nat. Commun. 2017, 8, 1-8. [CrossRef] [PubMed]

107. Zhang, C.; Koros, W.J. Zeolitic Imidazolate Framework-Enabled Membranes: Challenges and Opportunities. J. Phys. Chem. Lett. 2015, 6, 3841-3849. [CrossRef]

108. Knebel, A.; Geppert, B.; Volgmann, K.; Kolokolov, D.I.; Stepanov, A.G.; Twiefel, J.; Heitjans, P.; Volkmer, D.; Caro, J. Defibrillation of Soft Porous Metal-Organic Frameworks with Electric Fields. Science 2017, 358, 347-351. [CrossRef] [PubMed]

109. Zhou, S.; Wei, Y.; Li, L.; Duan, Y.; Hou, Q.; Zhang, L.; Ding, L.X.; Xue, J.; Wang, H.; Caro, J. Paralyzed Membrane: Current-Driven Synthesis of a Metal-Organic Framework with Sharpened Propene/Propane Separation. Sci. Adv. 2018, 4, 1-9. [CrossRef]

110. Hou, Q.; Wu, Y.; Zhou, S.; Wei, Y.; Caro, J.; Wang, H. Ultra-Tuning of the Aperture Size in Stiffened ZIF-8_Cm Frameworks with Mixed-Linker Strategy for Enhanced $\mathrm{CO}_{2} / \mathrm{CH}_{4}$ Separation. Angew. Chemie Int. Ed. 2019, 58, 327-331. [CrossRef]

111. Moreno-Vilet, L.; Bonnin-Paris, J.; Bostyn, S.; Ruiz-Cabrera, M.A.; Moscosa-Santillán, M. Assessment of Sugars Separation from a Model Carbohydrates Solution by Nanofiltration Using a Design of Experiments (DoE) Methodology. Sep. Purif. Technol. 2014, 131, 84-93. [CrossRef]

112. Didaskalou, C.; Kupai, J.; Cseri, L.; Barabas, J.; Vass, E.; Holtzl, T.; Szekely, G. Membrane-Grafted Asymmetric Organocatalyst for an Integrated Synthesis-Separation Platform. ACS Catal. 2018, 8, 7430-7438. [CrossRef] 
113. Valtcheva, I.B.; Marchetti, P.; Livingston, A.G. Crosslinked polybenzimidazole membranes for organic solvent nanofiltration (OSN): Analysis of crosslinking reaction mechanism and effects of reaction parameters. J. Memb. Sci. 2015, 493, 568-579. [CrossRef]

114. Marchetti, P.; Butté, A.; Livingston, A.G. Quality by Design for Peptide Nanofiltration: Fundamental Understanding and Process Selection. Chem. Eng. Sci. 2013, 101, 200-212. [CrossRef]

115. Lee, M.J.; Kwon, H.T.; Jeong, H.K. High-Flux Zeolitic Imidazolate Framework Membranes for Propylene/Propane Separation by Postsynthetic Linker Exchange. Angew. Chemie Int. Ed. 2018, 57, 156-161. [CrossRef] [PubMed]

116. Ma, X.; Lin, Y.S.; Wei, X.; Kniep, J. Ultrathin Carbon Molecular Sieve Membrane for Propylene/Propane Separation. AIChE J. 2016, 62, 491-499. [CrossRef]

117. Huang, Y.; Merkel, T.C.; Baker, R.W. Pressure Ratio and Its Impact on Membrane Gas Separation Processes. J. Memb. Sci. 2014, 463, 33-40. [CrossRef]

118. Merkel, T.C.; Lin, H.; Wei, X.; Baker, R. Power Plant Post-Combustion Carbon Dioxide Capture: An Opportunity for Membranes. J. Memb. Sci. 2010, 359, 126-139. [CrossRef]

119. Ma, X.; Williams, S.; Wei, X.; Kniep, J.; Lin, Y.S. Propylene/Propane Mixture Separation Characteristics and Stability of Carbon Molecular Sieve Membranes. Ind. Eng. Chem. Res. 2015, 54, 9824-9831. [CrossRef]

120. James, J.B.; Lin, Y.S. Kinetics of ZIF-8 Thermal Decomposition in Inert, Oxidizing, and Reducing Environments. J. Phys. Chem. C 2016, 120, 14015-14026. [CrossRef]

121. James, J.B.; Lin, Y.S. Thermal Stability of ZIF-8 Membranes for Gas Separations. J. Memb. Sci. 2017, 532, 9-19. [CrossRef]

122. Zhang, H.; James, J.; Zhao, M.; Yao, Y.; Zhang, Y.; Zhang, B.; Lin, Y.S. Improving Hydrostability of ZIF-8 Membranes via Surface Ligand Exchange. J. Memb. Sci. 2017, 532, 1-8. [CrossRef]

123. Zhang, H.; Liu, D.; Yao, Y.; Zhang, B.; Lin, Y.S. Stability of ZIF-8 Membranes and Crystalline Powders in Water at Room Temperature. J. Memb. Sci. 2015, 485, 103-111. [CrossRef]

124. Kwon, H.T.; Jeong, H.K.; Lee, A.S.; An, H.S.; Lee, J.S. Heteroepitaxially Grown Zeolitic Imidazolate Framework Membranes with Unprecedented Propylene/Propane Separation Performances. J. Am. Chem. Soc. 2015, 137, 12304-12311. [CrossRef] [PubMed]

125. Krokidas, P.; Castier, M.; Moncho, S.; Sredojevic, D.N.; Brothers, E.N.; Kwon, H.T.; Jeong, H.K.; Lee, J.S.; Economou, I.G. ZIF-67 Framework: A Promising New Candidate for Propylene/Propane Separation. Experimental Data and Molecular Simulations. J. Phys. Chem. C 2016, 120, 8116-8124. [CrossRef]

126. Bux, H.; Chmelik, C.; Krishna, R.; Caro, J. Ethene/Ethane Separation by the MOF Membrane ZIF-8: Molecular Correlation of Permeation, Adsorption, Diffusion. J. Memb. Sci. 2011, 369, 284-289. [CrossRef]

127. James, J.B.; Wang, J.; Meng, L.; Lin, Y.S. ZIF-8 Membrane Ethylene/Ethane Transport Characteristics in Single and Binary Gas Mixtures. Ind. Eng. Chem. Res. 2017, 56, 7567-7575. [CrossRef]

128. Li, Y.S.; Liang, F.Y.; Bux, H.; Feldhoff, A.; Yang, W.S.; Caro, J. Molecular Sieve Membrane: Supported Metal-Organic Framework with High Hydrogen Selectivity. Angew. Chemie Int. Ed. 2010, 49, 548-551. [CrossRef]

129. Li, Y.; Liang, F.; Bux, H.; Yang, W.; Caro, J. Zeolitic Imidazolate Framework ZIF-7 Based Molecular Sieve Membrane for Hydrogen Separation. J. Memb. Sci. 2010, 354, 48-54. [CrossRef]

130. Aceituno Melgar, V.M.; Kwon, H.T.; Kim, J. Direct Spraying Approach for Synthesis of ZIF-7 Membranes by Electrospray Deposition. J. Memb. Sci. 2014, 459, 190-196. [CrossRef]

131. Gücüyener, C.; van den Bergh, J.; Gascon, J.; Kapteijn, F.; Gücüyener, C.; van den Bergh, J.; Gascon, J.; Kapteijn, F. Ethane/Ethene Separation Turned on Its Head: Selective Ethane Adsorption on the Metal-Organic Framework ZIF-7 through a Gate-Opening Mechanism. J. Am. Chem. Soc. 2010, 132, 17704-17706. [CrossRef] [PubMed]

132. Noro, S.I.; Tanaka, D.; Sakamoto, H.; Shimomura, S.; Kitagawa, S.; Takeda, S.; Uemura, K.; Kita, H.; Akutagawa, T.; Nakamura, T. Selective Gas Adsorption in One-Dimensional, Flexible CuII Coordination Polymers with Polar Units. Chem. Mater. 2009, 21, 3346-3355. [CrossRef]

133. Férey, G.; Serre, C. Large Breathing Effects in Three-Dimensional Porous Hybrid Matter: Facts, Analyses, Rules and Consequences. Chem. Soc. Rev. 2009, 38, 1380-1399. [CrossRef] [PubMed]

134. Jin, H.; Li, Y. Flexibility of Metal-Organic Frameworks for Separations: Utilization, Suppression and Regulation. Curr. Opin. Chem. Eng. 2018, 20, 107-113. [CrossRef]

135. Yang, J.; Zhang, Y.B.; Liu, Q.; Trickett, C.A.; Gutiérrez-Puebla, E.; Monge, M.Á.; Cong, H.; Aldossary, A.; Deng, H.; Yaghi, O.M. Principles of Designing Extra-Large Pore Openings and Cages in Zeolitic Imidazolate Frameworks. J. Am. Chem. Soc. 2017, 139, 6448-6455. [CrossRef] 
136. Eum, K.; Jayachandrababu, K.C.; Rashidi, F.; Zhang, K.; Leisen, J.; Graham, S.; Lively, R.P.; Chance, R.R.; Sholl, D.S.; Jones, C.W.; et al. Highly Tunable Molecular Sieving and Adsorption Properties of Mixed-Linker Zeolitic Imidazolate Frameworks. J. Am. Chem. Soc. 2015, 137, 4191-4197. [CrossRef]

137. Thompson, J.A.; Brunelli, N.A.; Lively, R.P.; Johnson, J.R.; Jones, C.W.; Nair, S. Tunable $\mathrm{CO}_{2}$ Adsorbents by Mixed-Linker Synthesis and Postsynthetic Modification of Zeolitic Imidazolate Frameworks. J. Phys. Chem. C 2013, 117, 8198-8207. [CrossRef]

138. Thompson, J.A.; Blad, C.R.; Brunelli, N.A.; Lydon, M.E.; Lively, R.P.; Jones, C.W.; Nair, S. Hybrid Zeolitic Imidazolate Frameworks: Controlling Framework Porosity and Functionality by Mixed-Linker Synthesis. Chem. Mater. 2012, 24, 1930-1936. [CrossRef]

139. Hillman, F.; Brito, J.; Jeong, H.K. Rapid One-Pot Microwave Synthesis of Mixed-Linker Hybrid Zeolitic-Imidazolate Framework Membranes for Tunable Gas Separations. ACS Appl. Mater. Interfaces 2018, 10, 5586-5593. [CrossRef]

(C) 2018 by the authors. Licensee MDPI, Basel, Switzerland. This article is an open access article distributed under the terms and conditions of the Creative Commons Attribution (CC BY) license (http://creativecommons.org/licenses/by/4.0/). 